UNIVERSIDADE DE SÃO PAULO

FACULDADE DE ODONTOLOGIA

\title{
INFLUÊNCIA DO MODO DE ARMAZENAMENTO E DO TIPO DE ADESIVO NA MICROINFILTRAÇÃO DE DENTES DECÍDUOS RESTAURADOS COM RESSINA COMPOSTA
}

Eloisa Lorenzo de Azevedo Ghersel

Dissertação apresentada à Faculdade de Odontologia da Universidade de São Paulo, para concorrer ao Título de Mestre, pelo convênio Interinstitucional entre a Universidade de São Paulo e a Universidade Federal de Mato Grosso do Sul.

Área de Concentração: Odontopediatria. 
Data da defesa:

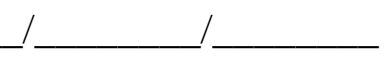

\section{Banca Examinadora}

Prof. Dr.

Nota: ___ (_ _ Assinatura:

Prof. Dr.

Nota: ___ (_ Assinatura:

Prof. Dr.

Nota:___ (_ Assinatura:

Menção: 


\section{DEDICATÓRIA}

\section{Aos meus pais}

Waldeck e Thereza que foram vitoriosos na difícil arte de educar os filhos e que souberam mostrar que exclusivamente com trabalho e determinação é possível alcançar nossos objetivos. Sem vocês eu jamais concluiria esta etapa da minha vida.

Tito e Geny que me ajudaram de maneira incondicional e de quem jamais ouvi a palavra "não”, nos momentos em que mais precisei.

\section{Ao meu marido Herbert}

Que de forma carinhosa sempre esteve ao meu lado, me estimulando e me apoiando em tudo que fosse necessário, reconheço que não poderia ter tido prova maior de seu amor.

\section{Às minhas filhas Lorena e Amanda}

Razão da minha existência, a quem impus minha ausência, espero que um dia me compreendam. 



\section{À Professora Dra. Ana Lídia Ciamponi Fernandes}

Martins, pelo exemplo de pessoa humana, pelo desprendimento, boa vontade e orientação no desenvolvimento deste trabalho, meu sincero reconhecimento.

Ao Professor Dr. Antônio Carlos Guedes Pinto, por nos proporcionar a possibilidade de crescermos profissionalmente, assim como pela responsabilidade e segurança com que me orientou neste trabalho. 


\section{AGRADECIMENTOS}

$>$ À Professora Dra. Catarina Prado, minha mestre e amiga sincera, por ter trabalhado intensamente na elaboração do primeiro projeto de Curso de Mestrado para a UFMS e, que só foi florescer, muito tempo depois de ela ter lançado a viçosa semente.

Ao Professor Dr. Tito Ghersel, maior responsável pela realização deste curso, que trouxe grandes benefícios para inúmeras pessoas.

À Professora Dra. Célia Regina M. D. Rodrigues, pela brilhante forma em que nos conduziu durante o curso.

Aos professores e funcionários do Departamento de Odontopediatria da FOUSP, pelos ensinamentos transmitidos e pela boa acolhida que nos foi dispensada.

Aos Professores Antônio Muench e Tito Ghersel, pelo inestimável auxílio prestado na elaboração da estatística. 
> À Professora Siva Geny Ghersel, pelo trabalho de revisão ortográfica.

Aos professores e funcionários dos Departamentos de Dentística e Estomatologia da FOUSP, pela orientação e permissão do uso dos equipamentos necessários para a realização da parte experimental.

Às amigas e colegas Letícia Morettini, Magali Trivelato, Luíza Amélia Trevisan e Míriam Mourão e aos alunos do curso de graduação de Odontologia da UFMS, que me auxiliaram na coleta dos dentes decíduos usados neste estudo.

> Às amigas e colegas Mônica Aratani e Míriam Mourão, pelas brilhantes idéias e sugestões tão oportunas.

$>$ À Helena, Luíza e Maria Elisa, pelo amor, apoio, companheirismo e por compartilharem comigo os meus sucessos.

À Maria Isabel e Andréia Paula, pelo profissionalismo com que desempenharam o seu trabalho, auxiliando-me diretamente nestes três anos de curso. 
Aos meus amigos e colegas Elizete Barros, Jussara Ennes, Cibele e Paulo Zárate, pelos momentos de alegria compartilhados em São Paulo.

A todos que, direta ou indiretamente, contribuíram para a realização deste trabalho. 


\section{SUMÁRIO}

p.

RESUMO

1. INTRODUÇÃO …................................................................

2. REVISÃO DA LITERATURA …...............................................

3. PROPOSIÇÃO …....................................................................41

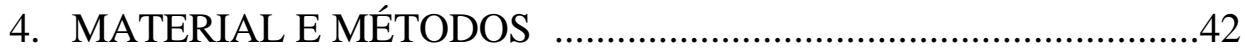

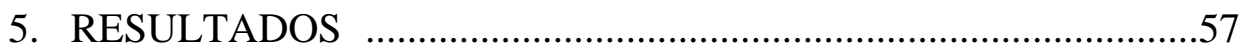

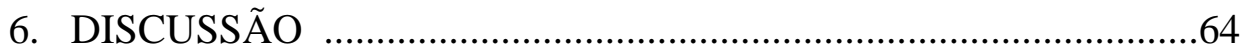

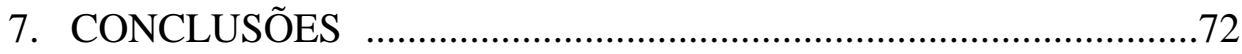

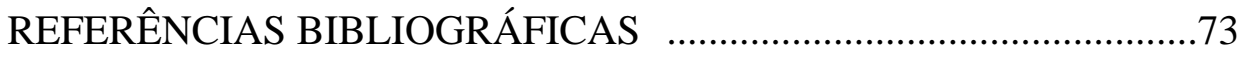

SUMMARY

APÊNDICE 


\section{LISTA DE FIGURAS}

Figura 1 - Máquina de ciclagem térmica

Figura 2 - Máquina politriz utilizada para o aplainamento da resina de inclusão das amostras.

Figura 3 - Máquina de seccionamento Labcut 1010, utilizada para o seccionamento final das amostras. 54

Figura 4 - Micro computador e scanner com software Diracon III, para a medição dos valores de microinfiltração nas amostras. 55

Figura 5 - Amostra incluída na resina, após o corte, demonstrando a penetração do corante nas interfaces das paredes axial e cervical. 57

Figura 6 - Amostra incluída na resina, após o corte, demonstrando menor infiltração do corante nas interfaces das paredes axial e cervical. 58

Figura 7 - Amostra incluída na resina, após o corte, demonstrando ausência de infiltração do corante nas interfaces das paredes axial e cervical. 58 
Gráfico 1 - Distribuição das médias de microinfiltração em milímetros correspondentes ao modo de armazenamento 61

Gráfico 2 - Distribuição das médias de microinfiltração em milímetros correspondentes ao material 61

Gráfico 3 - Distribuição das médias de microinfiltração em milímetros correspondentes à interface 62

Gráfico 4 - Distribuição das médias de microinfiltração em milímetros correspondente à interação armazenamento $\mathrm{x}$ material $\mathrm{x}$ interface 63 


\section{LISTA DE TABELAS}

Tabela 5.1 - Análise de variância dos valores de microinfiltração correspondentes aos fatores principais armazenamento, adesivo e interface e suas interações 59

Tabela 5.2 - Médias de microinfiltração em milímetros correspondentes aos fatores principais: armazenamento, material e interface 60

Tabela 5.3 - Médias de microinfiltração em milímetros correspondentes à interação: armazenamento $\mathrm{x}$ material $\mathrm{x}$ interface, e valor crítico para contraste 63 


\section{LISTA DE ABREVIATURAS}

${ }^{\circ} \mathrm{C}$ - graus Celsius

$\mu \mathrm{m}$ - micrômetro

$\mathrm{MPa}$ - mega pascal

EDTA - etileno diamino tetra-acético

$\mathrm{NaF}$ - fluoreto de sódio

pH - potencial de Hidrogenização

Min.- minuto

MEV - microscópio eletrônico de varredura

mm - milímetros

mm Hg - milímetros de mercúrio

$\mathrm{mm}^{2}$ - milímetros quadrados

BIS-GMA - bisfenol glicidil metacrilato

USA - United States of America

FOUSP - Faculdade de Odontologia da Universidade de São Paulo

rpm - rotação por minuto

LIDO - Laboratório de Informática Dedicado a Odontologia 


\section{RESUMO}

\section{Influência do modo de armazenamento e do tipo de adesivo na microinfiltração de dentes decíduos restaurados com resina composta}

No presente trabalho foi feita uma avaliação, in vitro, da influência do modo de armazenamento e de dois tipos de adesivos dentinários na microinfiltração, em paredes axiais e cervicais de restaurações com resina composta, em segundos molares decíduos. As amostras foram divididos em três grupos de acordo com o tipo de armazenamento, denominados: Desidratado, Hidratado e Congelado. As amostras do grupo Desidratado foram mantidas secas, as do grupo Hidratado foram armazenadas em solução fisiológica em geladeira e as do grupo Congelado foram mantidas no freezer, também imersas em solução fisiológica. A seguir, as amostras receberam dois preparos cavitários do tipo slot vertical, um ocluso-mesial e o outro ocluso-distal. Nas cavidades ocluso-mesiais foi utilizado o sistema adesivo Scotchbond Multi-Uso, enquanto que nas ocluso-distais foi usado o adesivo monocomponente Prime \& Bond 2.1, sendo todas restauradas com a resina composta Solitaire. Os grupos foram, então, submetidos à ciclagem térmica, antes de serem 
imersos em solução de Nitrato de Prata. Para avaliação da penetração do corante na interface dente-restauração, as amostras foram seccionadas primeiro no sentido vestíbulo-lingual, depois incluídas em resina autopolimerizavável para adaptação na máquina de seccionamento para então, receberem um segundo corte, agora no sentido mésio-distal, no centro da restauração. Os valores da microinfiltração nas paredes axiais e cervicais foram mensurados através de um sistema de imagens digitalizadas, apresentados em milímetros $(\mathrm{mm})$ e, a seguir, submetidos a Análise de Variância. Os resultados obtidos demonstraram que o modo de armazenamento não teve influência estatisticamente significante na microinfiltração marginal das restaurações. A microinfiltração na parede cervical foi estatisticamente significante maior que na parede axial, com segurança de 99,9\%. Os adesivos utilizados não tiveram influência estatisticamente significante na microinfiltração, nos modos de armazenamento estudados. Porém, houve diferença estatisticamente significante nas amostras do grupo Desidratado, com o adesivo Prime \& Bond 2.1, considerando as margens da restauração (axial e cervical) 


\section{INTRODUÇÃO}

A perda da estrutura dentária, principalmente por cárie, tem sido um dos principais motivos de estudos, tanto que nas últimas décadas foram desenvolvidos materiais adesivos com o intuito de reparar os danos aos tecidos dentais e reabilitar o indivíduo devolvendo-lhe a estética e, sobretudo, a função.

O esmalte dental tem estrutura basicamente prismática, representada em $96 \%$ por minerais, $4 \%$ por água, além de traços proteicos. A dentina humana, por sua vez, é um tecido conjuntivo mineralizado, estruturalmente tubular que, quando completamente formado, compõe-se de $70 \%$ de substância inorgânica, $20 \%$ de substância orgânica e $10 \%$ de água por peso, ou 45\%, 33\% e 22\% por volume, respectivamente (Ten Cate, 1988). Em função dessas diferenças, o mecanismo de adesão à dentina torna-se muito mais complexo quando comparado ao esmalte prova disso, é o longo tempo de estudo dedicado ao desenvolvimento dos adesivos dentinários. 
Os sistemas adesivos têm sido aperfeiçoados, e a retenção micromecânica entre o esmalte e a resina composta serviu de modelo para estudos sobre adesão em dentina. Entretanto, a pressão e a umidade do fluido dentinário dificultam a retenção de resinas hidrofóbicas, tornando-se necessário o desenvolvimento de moléculas adesivas bifuncionais, para reagir quimicamente com os constituintes orgânicos e inorgânicos da dentina e, simultaneamente, polimerizar com a resina restauradora. Após o preparo cavitário, forma-se sobre a superfície dentinária uma camada denominada "lama dentinária" (smear layer) que atrapalha, sobremaneira a adesão, impedindo o contato entre o adesivo e a superfície da dentina. Os sistemas adesivos mais recentes preconizam o condicionamento ácido total da dentina, que remove a smear layer, abre os túbulos dentinários, aumenta a permeabilidade da dentina e descalcifica a dentina inter e peritubular. Após o condicionamento ácido é aplicado primer hidrofílico capaz de penetrar nas malhas do colágeno, reagir com o substrato dentinário e com a resina desprovida de carga que penetra na dentina preparada, polimerizando e formando uma camada intermediária híbrida, principal responsável pelo mecanismo de adesão desses sistemas.

Apesar de todos os esforços tecnológicos, não foi possível ainda produzir-se um sistema de adesão capaz de selar hermeticamente a união denterestauração. A penetração clinicamente não detectável de bactérias, fluidos, moléculas ou íons entre o material restaurador e o dente é definida como microinfiltração, que pode ocorrer com diferentes intensidades, gerando a descoloração das margens da restauração, recidivas de cárie, hipersensibilidade dental e estabelecimento de patologias pulpares. (Baratieri et al. 1998). 
Diante da dificuldade de avaliação da efetividade de sistemas adesivos a dentes humanos, diretamente na boca, as pesquisas descritas na literatura utilizam-se de dentes extraídos por razões diversas, trabalhados em laboratórios que buscam simular as condições bucais, para maior fidelidade de resultados.

Dentre as diversas técnicas para a avaliação da microinfiltração, as mais utilizadas em estudos in vitro incluem o uso de corantes, traçadores químicos, isótopos radioativos, pressão de ar, bactérias, análise de ativação de neutrons, microscopia eletrônica de varredura, técnicas de cáries artificiais e condutividade elétrica. Porém, nenhum dos métodos usados para a detecção de microinfiltração é ideal. Provavelmente, o mais prático e que produz um grau aceitável de confiança é a penetração de traçadores, apesar das desvantagens. Porém, quando comparados a outros métodos in vitro são efetivos, permitindo comparações equitativas entre diferentes técnicas e materiais restauradores (Alani \& Toh, 1997).

Não existe, também, um método padronizado de armazenamento de dentes extraídos e utilizados em pesquisas in vitro, nem um consenso entre os autores a respeito de qual a forma ideal de estocagem.

Diversos fatores podem alterar a permeabilidade dentinária, como o tempo decorrido entre a exodontia e a utilização dos dentes em testes, além da composição da solução utilizada para armazená-los. Portanto, a preocupação em eliminar essas variáveis tem sido constante. No caso específico da Odontopediatria, os dentes decíduos são utilizados para testes de laboratório onde se pretende avaliar a possibilidade de microinfiltração marginal após o uso de diferentes materiais dentários. Além da evolução nesse campo, o recurso de restaurações biológicas ou 
colagens de dentes, tem sido alternativa viável para crianças que perderam, precocemente, parte ou toda a coroa do dente decíduo.

Diante do exposto, é lícita a preocupação quanto ao modo de armazenagem associada aos diferentes materiais dentários, na avaliação da infiltração marginal dessas restaurações. 


\section{REVISÃO DA LITERATURA}

Inúmeras pesquisas para avaliação de novos materiais utilizados em dentística restauradora são realizadas in vitro, pela dificuldade de se fazer estudos clínicos diretamente na cavidade bucal do paciente. O grande desafio é reproduzir as condições bucais da forma mais fiel possível, pois muitas variáveis podem interferir nesse processo, principalmente o modo de armazenamento de dentes, como demonstra a literatura a seguir.

\subsection{Fatores que podem interferir nos dentes utilizados para pesquisas "in vitro"}

Em 1976, Outhwaite et al. estudaram o efeito das mudanças da área de superfície, da espessura, da temperatura e do tempo pós extração na permeabilidade da dentina humana. Fazendo uso de um aparelho de câmara dupla, discos de dentina de terceiros molares recém extraídos, sem esmalte ou cornos pulpares receberam iodo radioativo em uma das superfícies. Após infiltrar nos discos, o iodo foi sendo coletado continuamente para a medição da infiltração. Os resultados mostraram que dobrando-se a área da superfície foi dobrada a quantidade de iodo infiltrado, sendo 
que a proporção entre essas duas variáveis dependeu de quão perto da polpa o disco foi preparado. A redução na espessura da dentina, a partir do lado do esmalte resultou em maior aumento da permeabilidade, se comparada ao do lado da polpa. O aumento da temperatura da dentina em $10^{\circ} \mathrm{C}$ quase dobrou a permeabilidade ao iodo. Os autores constataram que o tempo decorrido entre a extração e o teste teve pouco efeito na permeabilidade da dentina medida in vitro.

Causton \& Johnson (1979), avaliaram a importância do tempo pós extração na resistência adesiva do cimento de policarboxilato à dentina. A resistência foi testada em cisalhamento, por ser um método de preparo rápido e permitir que a colagem fosse feita em apenas 5 minutos após a extração do dente. Foram utilizados 190 terceiros molares recém extraídos, não erupcionados, de pacientes de 18 a 25 anos. Imediatamente após a extração, 80 dentes foram imersos em solução salina isotônica, e 110 divididos em 11 grupos de dez dentes cada, que foram armazenados por mais de 24 horas em solução salina, contendo um pequeno cristal de timol, para inibir o crescimento bacteriano. O experimento foi dividido em duas etapas, inicialmente para se estudar as alterações que ocorrem nas primeiras horas após a extração e, a seguir, as alterações que ocorrem em dentes armazenados por períodos entre 24 horas e 65 dias após a extração, antes de serem colados. Os resultados mostraram que ocorrem alterações na adesividade, em diversos períodos após a extração. Observou-se que a resistência da adesão diminui cerca de $50 \%$ nos primeiros 250 minutos, cresce lentamente (cerca de 30\%) nos próximos 25 dias, diminui rapidamente no período de 25 a 30 dias, continuando a diminuir lentamente. Essas alterações poderiam, presumivelmente, ser adiadas com o uso de refrigeração para o armazenamento das amostras. Os autores afirmaram ainda que as alterações 
iniciais costumam ocorrer tão rapidamente, que o simples fato de levar o corpo de prova à temperatura ambiente para fazer a colagem pode produzir alterações consideráveis. Segundo os autores, a única direção a ser tomada é utilizar dentes frescos, 10 a 20 minutos após a extração, pois a dentina de dentes extraídos é substancialmente diferente daquela de dentes vivos.

Aboush \& Jenkins (1983) investigaram o efeito do armazenamento pós extração na resistência de adesão à dentina usando teste de tração, armazenamento em água destilada e cimento de ionômero de vidro para restauração. Foram utilizados terceiros molares extraídos, divididos em 5 grupos de 9 dentes. Como o preparo das amostras durou pelo menos 60 minutos, o primeiro grupo foi restaurado em $60-240$ minutos após a extração. Os outros grupos foram armazenados em água destilada contendo timol à temperatura ambiente, tendo sido preparados e restaurados em 3,7 , 30 e 60 dias após a extração. Foi utilizada a região do centro da superfície de dentina oclusal para o experimento. As diferenças entre as médias de todos os grupos estudados não foram significantes, exceto entre os grupos de dentes recém extraídos e aqueles de 30 e 60 dias. Esses resultados indicaram que não houve vantagem no uso de dentes armazenados no período de 1 a 4 horas após a extração.

Kimura et al. (1985) estudaram os efeitos do período de armazenamento pós extração e do tipo de substância (solução salina fisiológica a $4^{\circ} \mathrm{C}$ ou formalina a 10\%) utilizada na imersão dos dentes estocados para realização de testes de resistência da adesão de resina composta à dentina. Foram utilizados 130 terceiros molares hígidos, obtidos de pacientes com idades entre 18 e 28 anos. Após a extração, os dentes foram imediatamente imersos em solução salina fisiológica e 
mantidos a $4^{\circ} \mathrm{C}$ ou em solução de formalina a $10 \%$. Os autores avaliaram 13 períodos de armazenamento: 15 e $30 \mathrm{~min} ; 1,2,6,12$ e 24 horas; 1, 2, 4, 8 e 12 semanas; e 6 meses. Todos os dentes, exceto aqueles armazenados por 6 meses foram mantidos em solução salina, trocada a cada 24 horas. Os dentes armazenados por 6 meses foram imersos em solução de formalina. Foi avaliada a resistência à tração entre a dentina de dentes jovens recém extraídos e a resina composta. Quando os dentes foram armazenados em solução salina fisiológica, a resistência adesiva aos 15 minutos após a extração mostrou o menor valor. As amostras armazenadas em formalina por 6 meses obtiveram a mais alta resistência adesiva.

Mitchem \& Gronas (1986) avaliaram os possíveis efeitos que o tempo pós extração pode ter sobre testes de adesão, bem como a influência da espessura da camada de dentina remanescente. Foram testados 7 intervalos de tempo pós extração, de 1 hora a 26 dias. Os resultados do efeito do tempo pós extração sobre a adesão revelaram que não existe diferença significante entre os espaços de tempo de 1 hora e de 26 dias. Com relação aos efeitos da espessura da dentina, a análise de variância mostrou diferença significante na adesão entre as distâncias de 1,5 e 0,75 mm da polpa, sendo que a distância menor é aproximadamente $44 \%$ mais fraca. Isso não causa surpresa, pois os túbulos não só aumentam em diâmetro como também em número, com a aproximação da polpa. Esses resultados sugerem que a espessura da camada de dentina remanescente deve ser mencionada, quando estudos de adesão in vitro são realizados.

Crim \& Garcia-Godoy (1987) compararam os efeitos causados pelo tempo de armazenamento e duração dos ciclos térmicos sobre a microinfiltração de 
restaurações de resina composta e adesivos, submetendo dentes a 100 ou 1500 ciclos térmicos, imediatamente após a restauração, ou armazenando-os em água por 24 horas após o término da restauração, antes da ciclagem térmica. Os resultados indicaram que não houve diferença estatisticamente significante na microinfiltração entre as amostras cicladas imediatamente após a restauração e naquelas armazenadas em água por 24 horas, a despeito do número de ciclos a que as amostras foram submetidas. Foi observado, entretanto, que os dentes restaurados e ciclados imediatamente, apresentaram extensão de penetração do corante ligeiramente maior. Segundo os autores, isso pode ser atribuído à absorção potencial de água das resinas compostas e subsequente expansão da restauração, melhorando o selamento marginal.

Cooley \& Dodge (1989) realizaram estudo para comparar três adesivos (Gluma, Scotchbond 2 e Tenure) quanto à sua capacidade de adesão. Foram utilizados 10 dentes recém extraídos e 10 dentes com maior período pós extração. Os dentes recém extraídos foram conservados em solução salina a $0,9 \%$ e testados até 5 dias após a extração. Os dentes com maior período pós extração foram armazenados em formalina a 10\%, variando em idade a partir da extração, em até alguns anos. Os resultados demonstraram que não houve diferença estatisticamente significante entre os três adesivos testados e, portanto, que o meio e o período de armazenamento não influenciaram esses resultados. Porém, as médias numéricas sugeriram que dentre os três materiais testados, o sistema Gluma apresentou a menor resistência. O Scotchbond 2 apresentou os maiores valores de resistência de adesão em dentes armazenados em formalina, por um período maior. O sistema Tenure teve maior resistência de adesão em dentes recém extraídos acondicionados em solução 
salina. Os autores concluíram que muito mais que o período de armazenamento, o prazo de validade e a estabilidade dos materiais podem influenciar os resultados.

O objetivo do estudo de Retief et al. (1989) foi determinar os efeitos do período e do meio de armazenamento sobre a resistência da adesão ao cisalhamento do sistema Scotchbond 2/Silux à dentina. Molares permanentes humanos foram armazenados em formalina, cloramina a 1\%, etanol a 70\%, solução salina fisiológica, ou timol a $0,05 \%$. Foram preparadas 15 amostras, armazenadas em cada meio, dois dias após a extração e após 6 meses, sendo aplicados o Scotchprep Primer e o adesivo Scotchbond 2 à superfície da dentina, de acordo com as recomendações do fabricante. Cilindros de resina composta Silux foram preparados sobre a superfície de dentina tratada em um aparato especial. As amostras foram removidas 15 minutos após a polimerização e armazenadas em água destilada a $37^{\circ} \mathrm{C}$ por 24 horas, e a força de cisalhamento foi aplicada aos cilindros. As médias de resistência de adesão foram listadas em ordem decrescente de magnitude: solução salina fisiológica (após 6 meses de armazenamento); formalina (após 6 meses de armazenamento); solução salina fisiológica (2 dias de armazenamento); cloramina 1\% (após 6 meses de armazenamento); cloramina 1\% (2 dias de armazenamento); formalina (2 dias de armazenamento); timol (após 6 meses de armazenamento); etanol 70\% (após 6 meses de armazenamento); timol (2 dias de armazenamento); etanol 70\% (2 dias de armazenamento). Os resultados demonstraram que as amostras armazenadas em etanol e timol tiveram as mais baixas resistências adesivas. O tempo de armazenamento não demonstrou efeito significante sobre a resistência adesiva ao cisalhamento. 
Para determinar se o tempo após a extração dental influencia a resistência à tração de cimento de ionômero de vidro e de adesivo dentinário, Beech et al. (1991) utilizaram dentes recém extraídos e acondicionados em água, à temperatura ambiente. No período de 20 minutos após a extração, a superfície de dentina de quatorze dentes foi preparada e brackets ortodônticos foram colados com ionômero de vidro (Fuji II, GC); treze dentes foram trabalhados com o adesivo (Scotchbond Self Cure, $3 M$ ) e resina composta (Clearfill, Kuraray). As colagens foram rompidas por tração, e os valores obtidos foram de 3,7 MPa para o ionômero de vidro e 1,08 MPa para o sistema adesivo e resina composta. Estes dados foram singificantemente diferentes daqueles obtidos com dentes armazenados em água a $4^{\circ} \mathrm{C}$, durante vários meses. Os resultados mostraram que o tempo de armazenamento pode alterar significantemente a resistência adesiva à dentina.

Goodis et al. (1991) estudaram a influência do tempo sobre a permeabilidade dentinária e o efeito do meio utilizado para armazenamento de dentes estocados, com finalidade de pesquisas in vitro. Terceiros molares recém extraídos foram armazenados por uma semana em soluções de etanol a $70 \%$, formalina a $10 \%$, água destilada com timol e solução salina tamponada com timol. Segmentos de coroas foram preparados e a permeabilidade inicial medida. Cada amostra foi colocada em uma nova solução, idêntica à original e a permeabilidade reavaliada em dois períodos: 1, 4, 6 e 8 dias ou 1, 8, 15 e 22 dias. Nas amostras armazenadas em etanol e formalina, os valores de permeabilidade foram menores que naquelas armazenadas em água/timol ou solução salina/timol, porém a maioria das amostras mostrou aumento da permeabilidade com o aumento do tempo. Tanto os períodos, como as soluções de armazenamento tiveram efeito estatisticamente significantes 
com diferenças significantes entre as amostras armazenadas em água/timol e solução salina/timol, e as armazenadas em etanol e formalina. Assim, ficou evidenciado que o tipo de solução de armazenamento afeta a permeabilidade da dentina, em função do tempo.

Brännström et al. em 1992, avaliaram in vitro a influência do congelamento de dentes e o armazenamento em solução de cloramina a $1 \%$, nas propriedades de adesão do Vitrebond. Também compararam a capacidade de adesão do Vitrebond à dentina, após limpeza da cavidade com Tubulicid Red ou com spray de água. A análise dessas variáveis foi feita com base no número e tamanho de falhas cervicais em cavidades Classe II. Para tanto, foram preparadas cavidades Classe II em pré-molares humanos hígidos, em que a margem cervical do preparo ficou abaixo do limite amelo-cemento, sendo 31 cavidades em dentes congelados e 29 em dentes armazenados em solução de cloramina a 1\%. Os dentes, em ambas as condições de armazenamento foram designados para dois grupos. No primeiro, as cavidades foram limpas com spray de água e, no outro, com solução contendo EDTA a $0,2 \%$ e $\mathrm{NaF}$ a $1 \%$. Todas as cavidades foram forradas com Vitrebond e restauradas com resina composta P50. Foram analisados o comprimento e a largura da falhas, reveladas em 17 das 31 restaurações dos dentes congelados e em 22 das 29 restaurações dos dentes armazenados em cloramina. A microinfiltração foi significantemente maior nos dentes armazenados em cloramina. Não houve diferença estatisticamente significante na microinfiltração entre as cavidades limpas com água ou com o detergente contendo EDTA a $0,2 \%$ e fluoreto de sódio. A microinfiltração parece ser significantemente afetada pelas condições de armazenamento dos dentes extraídos. Os autores sugeriram que dentes destinados a 
experimentos para avaliação da resistência adesiva e microinfiltração, têm melhor conservação congelados do que armazenados em solução de cloramina a $1 \%$.

Goodis et al. (1993) avaliaram o efeito da solução e do tempo de armazenamento, por períodos de 8 dias a 6 meses, sobre a permeabilidade dentinária e a resistência de adesão. Os dentes foram guardados imediatamente após a extração em cinco soluções normalmente usadas: etanol a 70\%, formalina a 10\%, água destilada, água destilada com timol ou solução salina com timol. A permeabilidade e a resistência ao cisalhamento foram avaliadas em um esquema de medições repetidas, após 8 dias, 15 dias e após 6 meses. A permeabilidade dentinária variou de acordo com o tipo da solução e com o período de armazenamento, aumentando para a formalina, para $\mathrm{o}$ etanol e para as soluções baseadas em água, respectivamente. $\mathrm{O}$ armazenamento em solução salina resultou em diminuição significante da permeabilidade após longo período de armazenamento, sugerindo alterações na dentina. A resistência adesiva não foi afetada pelo período de armazenamento ou pelo tipo de solução, exceto para a solução salina. Assim, segundo os autores, os valores de permeabilidade e resistência de adesão podem ser afetados pelas condições de armazenamento. A solução salina, que é a mais utilizada em pesquisas de materiais odontológicos pode ser inadequada para o uso, pelo resultado de seu efeito sobre a permeabilidade dentinária e sobre a resistência de adesão.

O efeito do meio de armazenamento na microinfiltração marginal, em restaurações tipo Classe $\mathrm{V}$ com resina composta, foi estudado por Haller et al. (1993). As cavidades foram preparadas com a margem cervical em dentina ou 
cemento e restauradas com cinco diferentes agentes de adesão dentinária. Nessa pesquisa, foram utilizados molares humanos recentemente extraídos (grupo controle) e dentes armazenados por 3 a 4 semanas em cloramina $1 \%$, etanol $70 \%$, formalina $10 \%$ ou timol $1 \%$. As amostras armazenadas em formalina $10 \%$ apresentaram microinfiltração estatisticamente significante menor, quando comparadas ao grupo controle, provavelmente como resultado de ligação cruzada entre o colágeno e o formaldeído.

De acordo com Camps et al. (1994), para se utilizar dentes criopreservados em laboratório, o processo de criopreservação não deve modificar as propriedades funcionais dos dentes, em particular a permeabilidade dentinária, portanto testaram os efeitos da criopreservação sobre a permeabilidade dentinária humana. Foram utilizados 360 terceiros molares humanos recém extraídos, não cariados. Os dentes foram divididos em dois grupos: 180 dentes foram armazenados em solução salina tamponada a $4^{\circ} \mathrm{C}$ e avaliados 4 horas após a extração, e 180 dentes foram criopreservados. Os resultados demonstraram que a criopreservação não modificou a permeabilidade dentinária.

Burrow et al. (1994) investigaram a influência da idade e da profundidade da dentina, sobre a resistência à tração de três sistemas adesivos. Foram utilizados discos de dentina humana retirados de regiões próximas à polpa e mais distantes a esta, provenientes de dentes recém extraídos e daqueles com maior tempo de extração. Três sistemas adesivos, Scotchbond Multi-Uso, Superbond DLiner e Liner Bond II, foram avaliados. As variações estruturais da camada impregnada de resina, ou camada híbrida, foram comparadas entre as duas variáveis 
e os três sistemas adesivos. Os resultados indicaram que a idade e a profundidade da dentina não mostraram grande influência sobre a resistência adesiva com os novos tipos de sistemas adesivos. Acredita-se que a qualidade da camada híbrida, e não sua espessura, seja o fator mais importante para a obtenção de altos valores de resistência de adesão.

Watanabe \& Nakabayashi (1994) descreveram métodos utilizados para testes de adesão e a interferência de fatores que podem comprometê-la, como as condições de armazenamento a longo prazo. Os autores ressaltaram a importância do conhecimento das características da dentina, utilizadas em trabalhos in vitro. Discutiram o melhor método para a predição do desempenho clínico na avaliação da resistência de adesão, além da dificuldade em se propor um método de medição padronizado ótimo. Afirmaram, também, que as condições experimentais padrão in vitro, que podem simular as condições in vivo, ainda estão sob investigação.

Dentes extraídos foram armazenados em uma variedade de soluções, por diferentes períodos, antes de seu uso em estudos in vitro. O objetivo do estudo de Lam May Cheng \& Gulabivala (1996) foi avaliar a influência do período (12 horas, 1, 4 e 15 semanas) e tipo de armazenamento (solução salina, solução salina/formol, hipoclorito de sódio e dentes guardados a seco) no preparo do canal radicular, por instrumentos endodônticos padronizados. Apesar de o hipoclorito de sódio não ser utilizado como meio de armazenamento "per se", este é muitas vezes usado por períodos limitados de tempo para ajudar a remover tecidos moles aderidos. Uma, quatro e quinze semanas foram os tempos arbitrariamente selecionados para cobrir o período de armazenamento congelado e, o tempo zero semana, foi incluído como 
controle para comparações. Dentes recém extraídos foram imediatamente mantidos em meios de armazenamento e duração anteriormente referidos. Os resultados desse estudo sugerem que dos meios testados, a solução formol-salina a $4 \%$ foi a melhor. Porém, outros meios, como o congelamento, devem ser avaliados. Se foi utilizado um meio de armazenamento que altere as propriedades físicas do dente, a ponto de alterar a remoção de dentina, a padronização do período de armazenamento também é de importante consideração. Os autores concluíram que o armazenamento de dentes em solução salina, formol-salina, hipoclorito de sódio e a seco resultou em diferenças estatisticamente significantes no preparo do canal radicular, entre os grupos dos períodos de 1, 4 e 15 semanas. Além disso, houve diferenças altamente significantes entre os dentes armazenados nos períodos de $0,1,4$ e 15 semanas, nos meios hipoclorito de sódio e solução salina. Não houve diferenças significantes nos diferentes períodos de armazenamento, em dentes armazenados em formol-salina. De acordo com os autores, os resultados do grupo dos dentes mantidos secos mostraram diferenças significantes quando considerados os períodos de $0,1,4$ e 15 semanas.

Camps et al. (1996) avaliaram a influência da criopreservação e do tempo de armazenamento sobre a microinfiltração de dois agentes de união à dentina. Foram utilizados 80 terceiros molares humanos hígidos, extraídos, designados aleatoriamente para os seguintes grupos: dentes recém extraídos usados até duas horas após a extração; dentes congelados, armazenados em solução salina fosfatada a $4^{\circ} \mathrm{C}$ e criopreservados dentro de 4 horas; dentes refrigerados, armazenados a $4^{\circ} \mathrm{C}$, em água contendo cloramina a 0,5\% e usados após 12 dias, 48 dias, 127 dias ou 138 dias. Os resultados mostraram que não houve diferença estatisticamente significante 
entre os valores de microinfiltração, detectados em dentes recém extraídos, criopreservados ou refrigerados até 12 dias. Porém, esses resultados foram diferentes dos dados de microinfiltração obtidos com as amostras refrigeradas por 48, 127 ou 138 dias a $4^{\circ} \mathrm{C}$, pois houve um aumento quadruplicado na microinfiltração para essas amostras.

Para determinar os efeitos das soluções e do tempo de armazenamento sobre a dentina, Strawn et al. (1996) utilizaram métodos espectográficos, aplicados em 27 discos de dentina, preparados a partir de terceiros molares recém extraídos. Os corpos de prova foram analisados, de forma não destrutiva, em busca de alterações químicas da superfície, com espectroscopia especular de reflexão infravermelho, para medir as alterações nas propriedades ópticas das faixas ultravioleta, visível e infra-vermelho com espectrofotômetro antes e depois do armazenamento. As amostras foram armazenadas em água destilada com timol a 0,02\%, água purificada e filtrada, solução fosfato-salina com timol a $0,02 \%$, etanol a $70 \%$ ou formalina a 10\%, e avaliadas após $0,1,2,7,14,21$ e 28 dias, sempre armazenadas em solução fresca, após cada medição. As análises do espectro infra-vermelho não indicaram diferenças significantes nas posições dos picos de colágeno ou minerais para qualquer solução, em qualquer período. Não houve diferença significante na intensidade dos picos para a dentina armazenada em água destilada, água purificada e água filtrada, e para a solução fosfato-salina ao longo do tempo. Porém, diferenças nas propriedades ópticas dos discos de dentina foram detectadas. Os autores concluíram que alterações químicas da superfície e nas propriedades ópticas da dentina podem ocorrer, em função da solução e do tempo de armazenamento. 
Os conceitos de controle da infecção de dentes para pesquisas induziram Dewald (1997) a avaliar os efeitos da desinfecção ou esterilização de dentes extraídos. Foram investigados os efeitos da formalina, da esterilização química a quente (chemiclave), do autoclave, do óxido de etileno e da radiação gama como métodos de desinfecção e esterilização em dentes extraídos. Ficou demonstrado que o armazenamento em formalina foi efetivo para o propósito de controle de infecção, não podendo ser recomendado como meio de armazenamento para estudos sobre adesão à dentina, pela variabilidade nos resultados de testes de resistência adesiva. O óxido de etileno também não é recomendado, por sua ineficiência na esterilização dos dentes. Os métodos de esterilização química a quente e o autoclave são recomendados, por prevenirem a contaminação cruzada durante as pesquisas de adesão in vitro.

Hawkins et al. (1997) verificaram que a topografia da superfície radicular de dentes armazenados em solução salina e, subsequentemente tratados com ácido cítrico, difere da topografia da superfície radicular de dentes tratados imediatamente após a extração. Para esse estudo, um grupo de dentes foi colocado em solução salina e tratado após 6 semanas de armazenamento, enquanto outro foi tratado imediatamente após a extração. O tratamento consistiu na aplicação de solução de ácido cítrico a $30 \%$ e pH 1.6, por 5 minutos. Os resultados demostraram que seis semanas de armazenamento em solução salina, não interferiram na desmineralização da superfície radicular por ácido cítrico, de acordo com as análises feitas por microscópio eletrônico de varredura. 
Araújo et al. (1998) compararam o efeito de diferentes meios de armazenamento de dentes humanos recém extraídos e de bovinos, na infiltração marginal de restauração de resina composta. Foram selecionados 30 dentes terceiros molares humanos hígidos extraídos e 20 dentes bovinos. Foram divididos em 8 grupos e armazenados nas seguintes condições: Grupo I, dentes humanos em freezer até 20 dias; Grupo II, dentes humanos em formol a 10\% em geladeira; Grupo III, dentes humanos em azida de sódio a 0,02\% em geladeira; Grupo IV, dentes humanos em soro fisiológico em geladeira; Grupo $\mathrm{V}$, dentes humanos em água destilada à temperatura ambiente; Grupo VI, dentes humanos, deixados secos durante dois meses e rehidratados por uma semana em água comum, à temperatura ambiente; Grupo VII, dentes bovinos em freezer por 1 ano; Grupo VIII, dentes bovinos em freezer por 20 dias. Foram realizados preparos de Classe V em esmalte, nas faces vestibular e lingual de cada dente humano e na face vestibular do dente bovino. Os preparos foram restaurados com o sistema Single Bond e resina composta Z100 (3M). Os dentes foram submetidos a termociclagem de 300 ciclos, entre mais ou menos $5^{\circ} \mathrm{C}$ e $55^{\circ} \mathrm{C}$. O corante utilizado foi a Rodamina B a $0,2 \%$ e o grau de infiltração marginal foi analisado em lupa estereoscópica, utilizando escores de 0 a 4 . Foi aplicada a análise estatística de Kruskal-Wallis. Os resultados demonstraram que os dentes bovinos, armazenados em freezer por 20 dias mostraram o menor grau de infiltração marginal; os dentes humanos, armazenados em água destilada e dentes secos, rehidratados, induziram o maior grau de infiltração; os demais meios de armazenamento mostraram desempenho intermediário. 


\subsection{Utilização de materiais adesivos e resina composta em restaurações dentárias}

Tendo em vista que as margens das restaurações não são fixas e inertes, com bordas impenetráveis, mas possuem fissuras microdinâmicas contendo trânsito ativo de íons e moléculas e, que a microinfiltração pode comprometer o sucesso clínico das restaurações dentárias, diversas pesquisas são realizadas in vitro, pela dificuldade de se realizar testes diretamente na boca do paciente. Com a evolução dos materiais adesivos houve melhoras significantes na qualidade das restaurações com resina composta, em relação à microinfiltração. Os trabalhos que se seguem, demonstram que inúmeras pesquisas têm sido dedicadas a essa área.

Para Smith et al. (1978) o controle da microinfiltração pode ser conseguido simplesmente às custas das características estruturais dos dentes, que funcionam como barreiras naturais, assim como pelas restaurações executadas sem interferência de contaminação, contando-se também com a destreza na técnica restauradora.

Nakabayashi et al. (1982) estudaram a efetividade de 4-metacriloxietiltrimelitato anidrido (4-META) na adesão de um bastão acrílico à dentina e ao esmalte condicionados. Observaram que monômeros com radicais hidrófobos e hidrofílicos, como o 4-META, foram capazes de promover a infiltração de monômeros no tecido duro. Os monômeros infiltrados polimerizaram in situ, com boa adesão aos substratos dentários. Estudos de microscopia eletrônica de varredura sugerem que os monômeros possuem afinidade com o tecido duro. Portanto, a boa adesão não foi produzida exclusivamente por embricamento mecânico nos túbulos dentinários, como foi considerado previamente. 
Para Wu et al. (1983), o grau de microinfiltração entre a restauração e a parede da cavidade é difícil de ser quantificado objetivamente. Os autores utilizaram um método de tingimento por prata, em comparação ao método de radioisótopos, com resultados que indicam definição superior e avaliação mais fiel da microinfiltração. Além da fidelidade, o registro da infiltração pode ser refinado e dividido em números mais precisos, e os dentes podem ser observados diretamente em microscópio, sem a necessidade de recursos de interpretação indireta de filmes ou fotografias.

Vieira (1991) avaliou, in vitro, a infiltração marginal na parede cervical de restaurações de Classe II, em molares decíduos, utilizando duas técnicas de aposição e polimerização de resina composta fotoativada. Pesquisou, também, a influência do preparo mecânico da superfície cavo-superficial da parede cervical e o influxo do forramento da cavidade com cimento de ionômero de vidro, na infiltração marginal, além do efeito da ciclagem térmica na adaptação material restaurador/dente. Os resultados denotaram que não houve diferença estatisticamente significante entre a infiltração marginal ocorrida em molares decíduos restaurados pela técnica convencional e pela técnica proposta por Lutz. Esta técnica consiste na colocação de um incremento na cervical, polimerizado através de cunha reflexiva e os demais incrementos polimerizados por vestibular, lingual e por oclusal. $\mathrm{O}$ biselamento da parede cervical não influenciou os níveis de infiltração marginal em ambas as técnicas. A presença do forramento com ionômero de vidro tendeu a diminuir significativamente a infiltração marginal, em relação à observada nas cavidades em que o forramento não foi realizado. E, finalmente, o número de 
defeitos encontrados na interface dente/restauração, de um modo geral aumentou após a ciclagem térmica.

Pashley et al. (1993) estudaram os efeitos da esterilização sobre a permeabilidade e resistência adesiva do cizalhamento à dentina, usando dentes humanos extraídos, que foram divididos aleatoriamente em três grupos. Os dentes do Grupo 1 não foram tratados e serviram como controle; os do Grupo 2, foram esterilizados em autoclave; e os dentes do Grupo 3, expostos a gás de óxido de etileno. Segmentos de coroas foram preparados a partir desses dentes, por ressecção das raízes na junção cemento-esmalte e no esmalte oclusal, para expor uma superfície de dentina plana. A permeabilidade da dentina mostrou-se similar em todos os grupos. A resistência de adesão ao cisalhamento foi similar nos 3 grupos, indicando que a esterilização dos dentes não altera a permeabilidade dentinária ou a resistência de adesão.

Futatsuki \& Nakata (1994) avaliaram a infiltração marginal em restaurações Classe II de resina composta pela fadiga térmica, nos limites cervical, proximal, vestíbulo-lingual e mésio-distal, usando premolares humanos, sem cáries, extraídos e acondicionados em solução neutra de formalina. Os resultados mostraram que o selamento nas margens cervicais foi significantemente melhorado pelo uso de materiais e métodos de adesão à dentina, quando comparado aos agentes de união convencionais. Entretanto, as margens proximais, na maioria das vezes apresentaram selamento menos efetivo que as oclusais. Os limites mésio-distais mostraram resultados menos favoráveis que os vestíbulo-linguais. Essa diferença entre as margens pode ocorrer pela eficácia de um bisel arredondado na margem 
cavo-superficial, pela diferença da espessura do esmalte da cavidade e pela natureza da luz de polimerização. Além disso, observou-se que o cimento de ionômero de vidro evitou a penetração do corante na dentina, no grupo da técnica do sanduíche, embora tenha sido observada a penetração do corante no esmalte em todas as amostras desse grupo.

Miranda Jr. (1994) estudou a ocorrência e intensidade da infiltração na interface dente restauração, através da margem gengival das caixas proximais em pré molares humanos extraídos. Foram utilizados dois tipos de resina composta e três adesivos. Os resultados demostraram que a resina composta $Z 100$ apresentou menor infiltração marginal que a Microfill; que a manutenção da umidade na superfície dentinária diminuiu a infiltração para a resina $Z 100$, com todos os adesivos; e que a aplicação da resina fluida Fortify (Bisco) reduziu significativamente a infiltração, tanto em esmalte quanto em dentina.

Tay et al. apresentaram, em 1995, um método não destrutivo para visualização direta de padrões de microinfiltração no interior da interface dentina/material restaurador, desmineralizados e corados com nitrato de prata. Foram realizados preparos Classe $\mathrm{V}$, tendo a margem oclusal em esmalte biselado e a margem cervical em dentina/cemento. Após a restauração com All Bond 2/P-50 e Scotchbond 2/Silux, armazenamento em água a $37^{\circ} \mathrm{C}$ por 7 dias e termociclagem com 300 ciclos, entre $5^{\circ} \mathrm{C}$ e $55^{\circ} \mathrm{C}$, as amostras foram imersas em solução de nitrato de prata. Após a fixação da prata, desmineralização e diafanização em metil salicilato, a localização das manchas de prata foi marcada normalmente. Os resultados demonstraram que a extensão da penetração de prata antes e após a desmineralização 
pelo ácido não foi estatisticamente significante. Esse estudo também confirmou que a microinfiltração não é uniforme ao redor da circunferência das margens da restauração. Embora o método seja intensivo para a microinfiltração que ocorre exclusivamente em esmalte, o conceito predominante sobre a ocorrência de microinfiltração em dentina, particularmente ao longo da borda cervical da restauração, representa uma alternativa para futuras investigações sobre a integridade do selamento marginal, em amostras restauradas in vivo.

Para Souza Jr. em 1995, houve avanços na qualidade dos materiais restauradores em relação à adesão às estruturas dentárias, após a introdução da técnica do condicionamento ácido do esmalte. A diferença estrutural entre o esmalte e a dentina induziu o desenvolvimento de novos sistemas adesivos específicos. Os adesivos dentinários têm sido estudados há muitos anos, com a finalidade de se obter uma união efetiva entre dentina e material restaurador, e foram classificados de acordo com a sua evolução em adesivos de primeira a quarta geração. O mecanismo de ação dos adesivos dentinários de quarta geração promove, inicialmente, a remoção da camada de "smear layer", descalcifica superficialmente a dentina inter e peritubular, e expõe a rede de fibras colágenas para posterior impregnação dessa área descalcificada por monômeros hidrofílicos.

Após estudo comparativo de quatro técnicas restauradoras com resina composta, Imparato, em 1996 avaliou os efeitos na microinfiltração marginal das caixas proximais, nas cavidades de Classe II, em molares decíduos. Os melhores resultados foram obtidos através da utilização de pequenos incrementos de resina 
composta, de aproximadamente 1,0 $\mathrm{mm}$ de espessura, no sentido vertical, visando amenizar a contração de polimerização.

Mello et al. (1996) estudaram dois tipos de tratamento da dentina, uma vez que podem influenciar a adesão. No primeiro grupo, a dentina foi tratada com ácido fosfórico a $10 \%$ durante 15 segundos, seguido da lavagem por 30 segundos, e da aplicação do adesivo Scotchbond 2 e da restauração com resina composta. No segundo grupo, a dentina foi lavada apenas com tergentol, previamente à aplicação do adesivo. Os resultados sugeriram que o tratamento da dentina com ácido fosfórico a 10\% previamente à aplicação do adesivo, diminuiu a infiltração marginal.

Uma revisão de literatura sobre o tecido dentinário humano, destacando sua formação, composição e entidades estruturais foi feita por Ruschel et al. (1996). As características da dentina decídua também foram relatadas, bem como as diferenças em relação à permanente, diferenças essas em relação à espessura, permeabilidade, dureza e alterações estruturais dentinárias e pulpares. Diante da literatura consultada, os autores puderam observar que a dentina é um tecido altamente susceptível às alterações sistêmicas ou provenientes do meio externo. No que se refere aos dentes decíduos, algumas peculiaridades próprias da dentina desses dentes indicam possíveis condutas clínicas, distintas daquelas adotadas aos permanentes.

A meta do estudo de Tay et al. (1996) foi avaliar o espectro micromorfológico que existe na interface resina-dentina, quando dois sistemas adesivos monocomponentes tipo primer/adesivo, com acetona, foram aplicados à dentina condicionada com ácido, sob diferentes condições de umidade e secagem. 
Foram utilizados 48 discos de dentina de $1 \mathrm{~mm}$, condicionados com ácido fosfórico a $10 \%$ e lavados por 20 segundos. As amostras foram divididas aleatoriamente em 4 grupos, baseados no estado de umidade da superfície remanescente: Grupo 1 (seco por 30 segundos), Grupo 2 (seco por 3 segundos), Grupo 3 (seco com mata-borrão) e Grupo 4 (molhado). O espectro micromorfológico dos dois sistemas de união foi essencialmente similar. Ambos foram afetados igualmente pela secagem suave (3 segundos), resultando em infiltração intertubular da resina incompleta. A menor infiltração foi conseguida quando a rede de colágeno foi deixada úmida, e parece relativamente imune à presença de excesso de umidade superficial. Por outro lado, a infiltração intratubular da resina foi severamente comprometida, na presença de excesso de água no interior dos túbulos dentinários e em suas aberturas, na dentina superficial. Portanto, a integridade superfícial ótima, para ambos os sistemas, parece depender de se conservar úmida a rede de colágeno, aliada à completa evaporação do excesso de água dos tecidos, antes da polimerização do primer/adesivo.

Namen et al. (1996) estudaram a contração de alguns adesivos dentinários. Os testes foram realizados in vitro com dentes humanos extraídos e os adesivos aplicados em condições recomendadas pelos respectivos fabricantes. No Grupo experimental foram alteradas essas recomendações e, tanto o primer quanto o adesivo de cada produto, permaneceram aplicados por 60 segundos antes da polimerização. Os corpos de prova foram examinados em microscopia eletrônica de varredura e os resultados demonstraram que todos os adesivos usados, de acordo com as recomendações do fabricante, apresentaram contração de polimerização. Entretanto, com alterações dessas recomendações, a contração de polimerização foi virtualmente eliminada. 
A proposta do trabalho de Perdigão et al. (1996) foi investigar, in vivo, a interação de seis sistemas de união à dentina. Os materiais One-Step, Clearfil Liner Bond 2, OptiBond, Permagen com ácido fosfórico a 10\%, Permagen com ácido fosfórico a $35 \%$ e Prime \& Bond foram aplicados a cavidades padrão Classe I oclusais em pré molares, com extração indicada por razão ortodôntica, combinando cada material com resina composta auto ou foto-polimerizável. Os dentes foram cuidadosamente extraídos 5 minutos após a polimerização e fixados em glutaraldeído a 2,5\%. Após a fixação, as amostras foram desidratadas, seccionadas e processadas para observação sob microscopia eletrônica de varredura (MEV) de emissão de campo. Apesar de alguns sistemas terem produzido superfícies intactas, sem falhas em amostras específicas, todos mostraram infiltração na transição entre a zona de interdifusão resina-dentina, com a resina fluida sobre estas.

A eficácia da união de cinco adesivos monocomponente comerciais e um experimental, foi avaliada por Finger \& Fritz (1996). Foram investigados os adesivos One-Step (BOS), Primabond (PAB), Prime \& Bond 2.0 (PB2), Solist (SOL), Tenure Quik (TEQ), um composto experimental (EXP) e uma resina composta híbrida. Foram avaliadas: a resistência de adesão ao cisalhamento à dentina humana, após 24 horas de imersão em água; a infiltração marginal e a espessura da camada híbrida. Os resultados demonstraram que os valores médios para a resistência de adesão ao esmalte ficaram entre 23 e $35 \mathrm{MPa}$ e, para dentina, entre 3,5 e $25 \mathrm{Mpa}$. Nem todas as restaurações com esses produtos apresentaram falhas e todos produziram camadas híbridas entre 2 e $10 \mu \mathrm{m}$ de espessura, entre a dentina e a restauração. Os adesivos com compostos de monômero, dimetacrilato e acetona se comportaram muito bem quando usados em técnica úmida. Sendo assim, os autores 
puderam afirmar que os agentes de união monocomponente com monômeros polimerizáveis hidrofílicos, são fáceis de usar e altamente efetivos.

Com o objetivo de determinar se os mais recentes sistemas adesivos, denominados "multiuso", poderiam ser utilizados associados a qualquer marca comercial de resina composta, Gonçalves et al. (1996) trabalharam com Scotchbond Multi-Purpose, Optibond Light Cure e Optibond Dual Cure, associados a três marcas diferentes de resina composta, submetendo-os a testes de resistência ao cisalhamento. Os resultados mostraram que as melhores associações foram obtidas com o Optibond Light Cure com a resina Herculite e com o Scotchbond Multi-Purpose com a resina $A P H$.

Tostes \& Guedes-Pinto (1996/97) avaliaram a microinfiltração de restaurações de Classe V, em dentes decíduos, com diferentes tempos de condicionamento ácido. Para tal, foram utilizados doze dentes decíduos hígidos e estocados em solução de formol a $1 \%$. Restaurações de Classe V, foram confeccionadas no terço cervical das faces vestibulares de cada dente. Os dentes foram divididos em dois grupos. No primeiro grupo, a dentina e o esmalte receberam condicionamento com solução de ácido fosfórico a 37\%, por 15 segundos e o segundo grupo foi tratado da mesma maneira, porém com o tempo de condicionamento ácido por 30 segundos. Os dentes foram restaurados com sistema adesivo Primer \& Bond 2.0 e resina TPH (Dentsply-Caulk), seguindo as recomendações do fabricante. As amostras foram imersas em solução de nitrato de prata e seccionadas, para a avaliação da penetração da prata. Os resultados 
demonstraram que não houve diferença estatisticamente significante na microinfiltração.

Gale \& Darvel (1997) realizaram estudo com o objetivo de criar traçados de alta resolução para a avaliação da microinfiltração. Para tanto, utilizaram 10 incisivos centrais intactos extraídos. Foram realizadas restaurações de resina composta associada a adesivos universais (Scotchbond MP, Z100, 3M) e, como traçador, o nitrato de prata, aplicado com vácuo inicial de $30 \mathrm{~mm} \mathrm{Hg.} \mathrm{Um} \mathrm{aparelho}$ específico removeu incrementos seriados de aproximadamente $100 \mu \mathrm{m}$ do dente, até que não houvesse traço do corante, e os dados das análises de imagens computadorizadas das superfícies foram usados para se construir mapas detalhados das interfaces. A penetração na interface variou de aproximadamente 0,3 a 1,6 mm em profundidade, e de 0,90 a 5,09 $\mathrm{mm}^{2}$ em área. O método proporcionou um mapeamento padronizado, de alta resolução, da penetração do corante na interface, sem a interferência da penetração tubular em dentina. Nenhuma das interfaces foi totalmente selada.

A efetividade dos adesivos dentinários hidrofílicos, no controle da microinfiltração marginal, foi testada por Pimenta \& Paiva em 1997. O objetivo do estudo foi avaliar qualitativamente a penetração de corante e a capacidade de controle da infiltração dos adesivos Scotchbond Multi-Purpuse Plus, Prime \& Bond 2.0 e o Paama 2. Foram utilizados 30 molares humanos recém extraídos, armazenados em formol 2\%. Os dentes, divididos em 3 grupos, foram restaurados com resina Z100, termociclados, imersos em fuccina básica, seccionados e, após esses procedimentos, procedeu-se à avaliação da penetração do corante. Os 
resultados mostraram que os três sistemas adesivos apresentaram um comportamento semelhante, reduzindo a microinfiltração, porém não foram capazes de impedi-la na margem cervical de restaurações Classe II em compósitos.

Holderegger et al. (1997) testaram a resistência de adesão ao cisalhamento de adesivos monocomponentes (Prime \& Bond 2.1, ART Experimental e Syntac Single Component) em dentina humana pressurizada. Comparados com agentes de união tradicionais (ART Bond e Syntac), os agentes de união monocomponente usados resultaram em valores de resistência de adesão ao cisalhamento maiores em dentina recém preparada. Entretanto, valores de resistência de adesão superiores às forças geradas durante a polimerização das resinas compostas, somente podem ser obtidos com aplicação dupla de agentes de união tradicionais.

Settembrini et al.(1997) compararam a microinfiltração do sistema adesivo monocomponente Prime \& Bond ao sistema bicomponente ProBond e a um controle. Foram usados no estudo 36 dentes permanentes recém extraídos, armazenados em solução de formalina a $10 \%$ por não mais de um mês, onde foram preparadas cavidades Classe $\mathrm{V}$, de forma que a margem oclusal da restauração ficasse em esmalte e a margem cervical em dentina. O Grupo 1 foi restaurado com resina composta sem agente de união; o Grupo 2, com Prime \& Bond e resina composta; e o Grupo 3, com ProBond e resina. As amostras foram termocicladas em fuccina para se avaliar o grau de microinfiltração, sendo observadas diferenças significantes entre o grupo sem agente de união e os grupos de Prime \& Bond e ProBond. Os resultados mostraram que o sistema de união monocomponente tem a 
capacidade de evitar a microinfiltração eficientemente, tanto na interface esmalterestauração como na dentina-restauração.

Ferrari et al. (1997) avaliaram a formação da camada híbrida, tags de resina e ramificações laterais adesivas, pelo uso de sistemas adesivos de última geração (monocomponentes) em esmalte e dentina, condicionados e não condicionados. Para isso, foram preparados planos de dentina, feitos na superfície de dentes vitais, aplicando-se os seguintes adesivos: Prime \& Bond 2.1, Single Bond e Syntac Sprint. Em três grupos, os sistemas monocomponentes foram aplicados seguindo as instruções dos fabricantes, enquanto que em outros três grupos, a dentina e o esmalte não foram tratados com o ácido fosfórico e o primer/adesivo foi aplicado diretamente sobre as superfícies preparadas. Sobre o primer/adesivo, foi aplicada uma fina camada de resina e polimerizada por 20 segundos. Os dentes da amostra foram extraídos imediatamente após a polimerização do material. Todas as amostras foram seccionadas em seu longo eixo e examinadas. Nos grupos que receberam o condicionamento com ácido fosfórico, todos os produtos testados mostraram o mesmo mecanismo de união micromecânica à dentina, como a formação de camada híbrida, tags de resina e ramificações laterais adesivas. Quando os sistemas adesivos foram aplicados à dentina não condicionada, a camada híbrida não se formou, os tags de resina foram notados raramente e sua forma foi fina, sem o selamento completo dos orifícios tubulares. Os túbulos permaneceram fechados, principalmente pelos tampões do smear layer. No esmalte, a superfície não condicionada mostrou ausência do padrão característico de condicionamento e de tags de resina. 
Segundo Schuckar \& Geurtsern (1997), muitos problemas acometem as restaurações de Classe II com resina composta. A contração inicial de polimerização, a diferença do coeficiente de expansão térmica entre material e tecidos dentais, dificuldades de acesso clínico à área proximal e problemas de adesão ao esmalte cervical são os principais fatores responsáveis pela infiltração marginal. Assim, os autores avaliaram a influência da localização da margem próximo-cervical sobre a adaptação e selamento marginal das restaurações de Classe II com resina composta. Também foi avaliada a existência de relação significante entre o tipo e a qualidade do condicionamento ácido do esmalte e o selamento próximo cervical; e entre os padrões de penetrações de resina na dentina e esse mesmo selamento. A adaptação e o selamento foram determinados antes e após a termociclagem, por exames em MEV e penetração de corante. Os resultados demonstraram que a adaptação próximo-cervical depende significantemente da posição da margem. Excelente selamento marginal foi encontrado na coroa a 1,0 mm da junção esmalte cemento em direção à oclusal, antes e depois da termociclagem, enquanto todos os outros grupos revelaram deterioração significante da integridade marginal após a termociclagem. O uso de adesivo dentinários melhorou significantemente o selamento marginal em cavidades com margens localizadas na junção esmaltecemento, antes e depois da termociclagem. Porém, a qualidade marginal não foi conseguida como nos casos com esmalte normalmente estruturado a 1,0 mm para oclusal da junção esmalte cemento, após condicionamento ácido. Em defeitos a 0,5 mm para apical da junção esmalte cemento o adesivo de dentina apenas melhorou a adaptação cervical antes da termociclagem. A avaliação das interfaces dente/restauração revelou que não houve diferença estatisticamente significante entre 
o padrão de condicionamento ácido do esmalte e o padrão de "tags" da dentina e o selamento marginal.

Em 1997, Bussadori pesquisou a microinfiltração em dentes decíduos, usando quatro materiais restauradores, associados ou não ao condicionamento ácido. Foram feitas dez restaurações para cada condição experimental. Os melhores resultados foram obtidos com Dyract, resina composta Z100, seguidos do Vitremer e Fuji II $L C$ e, em média, o condicionamento ácido não influiu nos valores de microinfiltração.

De acordo com Mathias et al. (1997), com a evolução das resinas compostas e por ter o dente decíduo uma vida útil menor, esse material tem se tornado uma opção para restaurações ocluso-proximais em preparos cavitários supragengivais. As cavidades devem ser executadas segundo as características dos preparos adesivos, que praticamente se limitam à remoção do tecido cariado. A face proximal deverá apresentar forma semelhante a uma gota com ângulos internos arredondados. Os preparos convencionais, por exigirem maior volume de material restaurador, favorecem os efeitos da contração de polimerização. Os adesivos dentinários auxiliam na diminuição da microinfiltração marginal, sendo que a margem gengival deve ser sempre localizada acima da margem livre da gengiva.

Alves et al. (1998) compararam a infiltração marginal em restaurações Classe II de molares decíduos, utilizando adesivo de 4⿳亠丷a geração (Scotchbond MultiUso, 3M) e resina composta híbrida tradicional $(Z-100,3 M)$ a uma resina de baixa viscosidade (Natural Flow, DFL). A resina de baixa viscosidade foi usada como base na parede cervical, seguida da complementação da restauração em direção à 
oclusal com a resina composta Z-100. Os resultados demonstraram diferentes graus de infiltração para ambos os materiais restauradores e não foi observada diferença estatisticamente significante entre eles.

A microinfiltração é a presença de íons, fluidos e bactérias na interface dente/restauração, afirmaram Baratieri et al. (1998). Geralmente ocorre em função da falta de adesão entre material restaurador e a cavidade, apresentando como componente patológico a infecção bacteriana da dentina e da polpa. Os sistemas adesivos melhoraram consideravelmente esses problemas, tendo em vista os resultados e as imagens obtidas em laboratório nos testes de adesão à estrutura dental. Entretanto, o ideal ainda não foi conseguido, pois os experimentos laboratoriais podem simular uma situação na boca, mas são limitados e não podem ser diretamente extrapolados para a clínica. Assim sendo, avaliações clínicas controladas a longo prazo se fazem necessárias, para confirmar o desempenho que esses materiais apresentam in vitro. Os sistemas adesivos são sensíveis à técnica e à manipulação e é preciso conhecer as suas limitações.

Groth et al. (1998) pesquisaram a resistência à tração, entre resina composta e dentina esterilizada por diferentes métodos, comparando-se com o grupo controle não estéril. Foram utilizados 48 terceiros molares humanos recém extraídos, divididos em 4 grupos de 12 dentes, onde o grupo 1 não foi submetido à esterilização; o grupo 2 foi esterilizado por calor seco; o grupo 3 foi esterilizado por calor úmido e o grupo 4 foi esterilizado por solução de glutaraldeído. Os dentes foram preparados e sobre a dentina condicionada com ácido fosfórico a 37\% foi aplicado sistema adesivo (Prime \& Bond 2.1), seguindo as instruções do fabricante. 
Logo após, foram restaurados com resina composta híbrida (TPH Spectrum). As amostras foram submetidas ao teste de resistência à tração. Após análise estatística, os resultados permitiram concluir que a estufa diminuiu, de forma estatisticamente significante, a resistência à tração da dentina, enquanto que a solução de glutaraldeído aumentou essa resistência. Não foi observada diferença significante entre o grupo controle e o grupo submetido a ciclo em autoclave.

Segundo Teruya \& Corrêa (1998), a técnica do condicionamento ácido do esmalte encerra detalhes que devem ser compreendidos e seguidos para segurança do sucesso clínico. Num passado recente, preconizava-se o tempo de 1 minuto. Atualmente, diversos estudos demonstram que se pode manter a efetividade adesiva de forma análoga, com tempo reduzido. O ácido fosfórico na concentração de 30 a 50\%, aplicado por 15 segundos, apesar de produzir superfícies morfologicamente distintas, apresenta resultados semelhantes quanto à resistência adesiva, quando aplicado por 60 segundos, tanto em dentes permanentes quanto em dentes decíduos. O tempo de condicionamento de 20 ou 30 segundos também é recomendado por muitos autores. O critério clínico para assegurar o condicionamento ácido adequado consiste na verificação da superfície opaco esbranquiçada, obtida após lavagem e secagem.

Desde o surgimento dos materiais híbridos, as resinas compostas alcançaram um platô em termos de desenvolvimento tecnológico, de acordo com Santos et al. (1998). Porém, em relação ao desenvolvimento de novos produtos, encontra-se em evidência o "PRIMM" (polymetric rigid inorganic matrix material). Esse material apresenta um novo conceito de resina fotoativada, pois é considerado 
condensável, tanto quanto o amálgama, característica importante na obtenção de ponto de contato interproximal. Outro fator positivo para essa resina é que ela permite maior profundidade de polimerização, podendo-se alcançar até $6 \mathrm{~mm}$ de profundidade de fotopolimerização, além de boa resistência ao desgaste. Em termos de composição, essa nova resina possui fase inorgânica constituída de uma rede fibrilar de alumina com diâmetro de no máximo $2 \mu \mathrm{m}$ e comprimento aproximado de $200 \mu \mathrm{m}$. A matriz pode ser tanto BIS-GMA quanto resina composta do tipo híbrida. A incorporação de mais um tipo de partículas de carga resultou em melhoras na condensabilidade do material. Os autores não fizeram comentários a respeito da contração de polimerização, nem sobre testes de microinfiltração com o referido material.

Cardoso \& Plácido (1998) avaliaram, in vitro, a microinfiltração de 8 novos adesivos universais introduzidos no mercado, Scotchbond MP Plus (SMP), Permaquick (PER), Optibond Fl (OFL), One Step (OS), Clearfill LB II (CLII, Prime \& Bond II (PBII), Solist (SOL), Single Bond (SB) e um adesivo hidrofóbico (ARM), como controle. Cavidades Classe V foram preparadas em molares humanos hígidos, com margens oclusais em esmalte e gengivais em dentina, e os adesivos foram aplicados de acordo com as instruções dos fabricantes. Todas as cavidades foram restauradas com resina composta Heliomolar RO. As amostras foram armazenadas em água a $37^{\circ} \mathrm{C}$ por 24 horas após terem recebido acabamento e polimento; foram submetidas à ciclagem térmica; seccionadas; avaliadas quanto à infiltração, segundo escala de 0 a 3 e analisadas estatisticamente. Nenhuma infiltração foi evidente nas margens em esmalte. O grupo controle $(A R M)$ teve os piores valores em relação a margens em dentina. Os adesivos $O S$ e $S O L$ foram os mais efetivos, seguidos pelo 
SB, OFL, PER, SMP e PBII. O CLII foi o menos efetivo, sem diferença estatística do ARM. Esses dados sugerem que esses novos sistemas adesivos são efetivos em selar as margens em esmalte, mesmo com técnicas diferentes e outros tipos de ácidos. Entretanto, nenhum deles eliminou completamente a infiltração nas margens em dentina, com exceção do One Step.

Leinfelder et al. (1998) reportaram a nova resina composta condensável, cuja partícula de carga é substancialmente mais grossa e texturizada que as convencionais. Essa característica torna a superfície mais áspera, e as partículas não fluem com facilidade umas sobre as outras, quando submetidas à carga. Como resultado, durante a inserção e condensação, é exigida uma pressão consideravelmente maior, para forçar o material no interior do preparo. Os autores compararam resina composta híbrida para dentes posteriores com a nova resina condensável (Solitaire $^{\circledR}$ ) e avaliaram a possibilidade de ser esta última, inserida como amálgama. Para limitar as variações clínicas encontradas em pacientes vivos, foi usado um manequim. Os resultados demonstraram que esse novo material pode ser inserido usando-se técnicas que são muito similares às do amálgama. Suas propriedades de manipulação permitem que sejam manuseadas mais facilmente do que as resinas convencionais ou mesmo o amálgama, proporcionando tempo de inserção e contorno proximal superiores às resinas convencionais. Os autores não fizeram referências quanto à contração de polimerização nem à microinfiltração.

De acordo com Resinas (1998), as resinas compostas condensáveis foram introduzidas recentemente como uma possível alternativa para o amálgama. Atualmente, existem no mercado 3 marcas disponíveis: Alert, Solitaire e SureFil. 
As resinas compostas condensáveis diferem das resinas compostas tradicionais, para dentes anteriores e posteriores, pelo aumento na quantidade de partículas inorgânicas. Estas partículas podem ser fibras (Alert), porosas (Solitaire) ou partículas irregulares (SureFil). O contato entre as partículas irregulares permite que a resina seja condensável, produzindo contatos interproximais aceitáveis em restaurações de Classe II. O material permite a inserção em um só incremento, em função da alta profundidade de polimerização e baixa contração de polimerização.

Poskus et al. (1998) analisaram o grau de polimerização e a qualidade da união ao dente de uma resina do tipo condensável, tendo como controle uma resina tradicional. Foram utilizados premolares humanos hígidos, nos quais realizaram-se cavidades proximais padronizadas. Metade das cavidades foi restaurada utilizando a resina condensável Alert $^{\circledR}(\mathrm{A})$, e a outra metade, a resina $Z-100^{\circledR} 3 M(\mathrm{Z})$. Duas técnicas de inserção foram utilizadas: incremental (I) e incremento único (U). Posteriormente, as amostras foram submetidas à ciclagem térmica e imersas em solução de azul de metileno a $0,5 \%$ por 4 horas. Os resultados demonstraram que houve diferença estatisticamente significante entre os grupos A-U (maior infiltração), Z-I (menor infiltração), A-I (menor infiltração) e Z-U (maior infiltração). Os resultados de microdureza foram submetidos à análise de variância, na qual não houve diferença entre as resinas estudadas. A Alert não permitiu maior profundidade de polimerização como anunciam os fabricantes e, em ambas as resinas, a camada cervical exibiu valores menores de dureza que a oclusal.

Vasconcelos \& Matson (1998) desenvolveram um método para mensurar a contração de polimerização linear em materiais foto-ativados, com o objetivo de 
simplificar outros dispositivos anteriormente utilizados. Os materiais usados foram as resinas Solitaire/Kulzer e Suprafill/SSWhite, além do compômero Dyract AP/Dentsply. Foram confeccionados 15 corpos de prova, onde foram realizadas duas marcações, cuja distância entre os referidos pontos foi medida antes e após a fotopolimerização. A seguir, os valores foram fornecidos por um perfilômetro conectado ao software do mesmo fabricante que provia os valores já calculados. Obtidos os resultados, aplicou-se o teste " $\mathrm{t}$ " de Student pareado ao nível de 0,05 de confiança, onde a resina Solitaire apresentou uma média, antes da polimerização, de 1,911 mm e após, de 1,882 mm; a Suprafill, 2,013 mm antes e 1,993 mm após, constatando-se que houve diferença estatisticamente significante, enquanto que no Dyract AP essa mesma diferença não foi encontrada. Em seguida, a análise de variância para as porcentagens de contração de polimerização das 3 marcas estudadas foi realizada. Os autores puderam afirmar que nos produtos Solitaire e Suprafill houve contração de polimerização, enquanto tal afirmação não pode ser aplicada ao Dyract AP.

Para Vianna et al. (1998), a evolução das resinas compostas e dos adesivos dentinários induziu muitos profissionais a elegê-los como materiais de escolha para restaurações proximais em dentes decíduos, apesar de não conseguirem superar completamente os problemas relativos ao desgaste na superfície oclusal e infiltração na região cervical. Porém, existem vantagens evidentes, como a economia de tecido dental, uma vez que os preparos passaram a limitar-se apenas à remoção do tecido cariado, ficando a retenção às expensas do condicionamento ácido do esmalte e da dentina, nas paredes do preparo cavitário. Os novos sistemas adesivos atuam removendo e solubilizando a smear layer, desmineralizando 
seletivamente e umedecendo a dentina remanescente, com monômeros resinosos hidrofílicos, através da dissolução causada pelos componentes ácidos do primer. A formação da camada híbrida aumenta a adesão entre resina e dentina. Os dentes decíduos e permanentes apresentam respostas diferentes aos condicionadores de dentina. O emprego do ácido fosfórico a $10 \%$ e do ácido maleico na mesma concentração causam a remoção da smear layer da dentina intertubular e dos túbulos dentinários, tanto nos decíduos como nos permanentes. A camada híbrida aparece em ambas as situações, porém ela é mais espessa nos dentes decíduos. Esses fatos também são influenciados pelo tempo de utilização dos condicionadores. Assim, recomenda-se que o primer seja aplicado por um período de tempo menor nos dentes decíduos do que nos permanentes. 


\section{PROPOSIÇÃO}

$\mathrm{O}$ presente trabalho tem como objetivo avaliar, in vitro, a microinfiltração na interface dente/restauração das paredes axial e cervical, em dentes decíduos restaurados com resina composta, tendo como variáveis a serem analisadas o modo em que esses dentes foram armazenados após a extração e também, dois tipos diferentes de adesivos dentinários. 


\section{MATERIAL E MÉTODOS}

\subsection{Instrumentais}

Cabo de bisturi

Caneta de alta rotação (MS 350 Dabi-Atlante)

Caneta de baixa rotação (Dabi-Atlante)

Cera utilidade (Duradent)

Compasso de ponta seca

Condensadores de resina tipo teflon (jogo com 3)

Cunha de madeira

Disco de carburundum

Disco de lixa para máquina politriz (BUEHLER) número 120.

Disco diamantado para máquina LABCUT 1010 EXTEC

Escova de naylon

Escova de Robson

Broca carbide FG-245 
Lâmina de bisturi n⿳015

Lixa de polimento e acabamento dental (3M)

Matriz transparente com porta matriz (TDV Dental Ltda)

Pedra Pomes

Pincel Microbrush (Micobrush Coporation, USA)

Ponta diamantada de granulação fina e extra fina (K.G.Sorensen)

Ponta diamantada esférica $1 / 4$ (K.G.Sorensen)

Recipiente de plástico do tipo coletor

Recipiente de vidro

Sistema de acabamento do tipo Enhance (Dentsply)

\subsection{Aparelhos}

Aparelho de ciclagem térmica pertencente ao Departamento de Dentística da Faculdade de Odontologia da universidade de São Paulo (FOUSP)

Autoclave marca LARCON

Fotopolimerizador de resina Translux (Kulzer Produtos Odontológicos)

Freezer - 320 litros (Brastemp) 
Máquina politriz de aplainamento $\left(\right.$ BUEHLER $\left.^{\circledR}\right)$, pertencente ao Departamento de Dentística da FOUSP

Máquina de seccionamento LABCUT 1010 EXTEC, pertencente ao Departamento de Dentística da FOUSP

Refrigerador - 440 litros (Brastemp)

Scanner e Microcomputador com software DIRACON III, pertencente ao Laboratório de Informática Dedicado a Odontologia (LIDO), Departamento de Estomatologia da FOUSP.

\subsection{Materiais}

Adesivo monocomponente fotopolimerizável: Prime \& Bond 2.1 (Dentsply)

Adesivo bicomponente fotopolimerizável: Scotchbond Multi-Uso (3M)

Água destilada (Pharmaceutica - Farmácia de manipulação)

Caneta esferográfica

Catalizador de resina acrílica autopolimerizável: Resigel - Luperox DDM (Redefibra) 
Dentes decíduos extraídos em época de esfoliação

Esmalte cosmético vermelho (Colorama)

Forma de gelo

Gel de ácido fosfórico a 37\%

Luminária portátil com lâmpada fluorescente

Óleo mineral para máquina LABCUT

Papel sulfite

Papel absorvente (Santepel)

Solução aquosa de cloreto de sódio $(\mathrm{NaCl})$ a 9/1000 (0,9\%). Uso externo (ADV)

Resina acrílica autopolimerizável Ortoclas (Clássico)

Resina acrílica autopolimerizável Resigel (Redefibra)

Resina composta Solitaire - A 10 (Kulzer)

Revelador fotográfico (Kodak)

Solução de nitrato de prata a 50\%, pH 6,7 (Pharmaceutica - Farmácia de manipulação)

\subsection{Seleção e preparo da amostra}


Foram selecionados vinte e quatro dentes segundos molares decíduos, hígidos, extraídos em época de esfoliação, obtidos do "Banco de Dentes" da Disciplina de Odontopediatria da FOUSP ou oriundos de crianças submetidas a tratamento odontológico em serviços de Saúde Pública, na cidade de Campo Grande, estado de Mato Grosso do Sul. Os dentes foram divididos aleatoriamente, em três grupos de oito e classificados de acordo com a forma de armazenamento em: Congelado, Hidratado e Desidratado.

Os dentes designados para os grupos Congelado e Hidratado foram aqueles obtidos em Campo Grande. Foi solicitado aos cirurgiões dentistas que procederam as exodontias, que apenas lavassem em água corrente e, a seguir, imergissem os dentes em soro fisiológico. No final do dia os dentes foram recolhidos e, imediatamente, retirados do local em que estavam armazenados e lavados novamente em água corrente, com escova de nylon, para remoção dos tecidos aderidos. Logo após, foram esterilizados em autoclave (Pashley et al., 1993; Duarte et al. (1995); Dewald,1997; Groth et al., 1998) por 20 minutos, a $121^{\circ} \mathrm{C}$. Os dentes pertencentes ao grupo Congelado foram imersos em soro fisiológico a $0,9 \%$, sem o uso de qualquer solução antibacteriana, num frasco plástico tampado e colocados no freezer (Beech et al., 1991; Camps et al., 1996), no máximo por 30 dias, tendo sido, 24 horas antes do início do trabalho colocado em refrigerador, para descongelamento. Os do grupo Hidratado foram colocados na mesma solução, em recipiente de vidro tampado, e mantidos no refrigerador (Araújo et al., 1998), no 
máximo por 30 dias, antes do trabalho de laboratório, sendo essa solução trocada a cada vinte e quatro horas.

Os dentes do terceiro grupo Desidratado, foram aqueles obtidos do Banco de Dentes que normalmente são mantidos secos, em recipientes plásticos. Após serem selecionados, esses foram lavados, esterelizados em autoclave, conforme citado anteriormente, e colocados em recipientes plásticos abertos, à temperatura ambiente, no máximo até 30 dias, para o início do trabalho. Uma hora antes de receber o preparo cavitário foram hidratados em água destilada.

\subsection{Preparo da superfície dental}

Todos os dentes foram retirados do local em que estavam armazenados, lavados em água corrente e secos com papel absorvente para, a seguir, receberem dois preparos cavitários, um ocluso-mesial e outro ocluso-distal. 


\subsection{Preparo Cavitário}

Para facilitar o manuseio, as amostras foram fixadas em lâmina de cera utilidade e, a seguir, preparadas cavidades de Classe II, do tipo slot vertical, preparos esses realizados em alta rotação com brocas carbide número 245, trocadas a cada três preparos, para que fosse possível manter a uniformidade em todas elas. As medidas da cavidade ficaram em torno de $3 \mathrm{~mm}$ de largura, por $3 \mathrm{~mm}$ de altura e $2 \mathrm{~mm}$ de profundidade, conferidas com um compasso de ponta seca, com o objetivo de preservar as devidas proporções. Os ângulos internos do preparo foram arredondados e os ângulos cavo-superficiais ficaram localizados em esmalte, inclusive os da parede cervical. Não foi realizado o bisel cavo superficial em esmalte (Mathias et al., 1997). Nesse ato, os dentes receberam a identificação através de pontos cuneiformes, na face vestibular, confeccionados com pontas diamantadas esféricas tamanho 1/4, para a determinação das situações de avaliação. 


\subsection{Procedimento Restaurador}

Após a confecção dos preparos cavitários, foi realizada a profilaxia das amostras com escova de Robson e pedra pomes, em baixa rotação, lavadas com jatos de água e secas com leves jatos de ar. Foi realizado o condicionamento com ácido fosfórico a 37\%, por 30 segundos (Tostes \& Guedes/Pinto, 1996-97), seguido da lavagem com spray ar/água, por 45 a 60 segundos. Foi procedida a secagem do dente com leves jatos de ar, evitando a desidratação da dentina. (Miranda Jr., 1994; Tay et al.,1996). Nas cavidades mésio-oclusais, foi utilizado o sistema adesivo Scotchbond Multi-Uso, de acordo com as recomendações do fabricante, através da aplicação do primer, com pincel do tipo Microbrush, em toda a área previamente condicionada, seguido de leve jato de ar. Em seqüência, foi aplicado o adesivo, cujos excessos também foram removidos com leves jatos de ar e fotopolimerizado por 20 segundos. Nas cavidades disto-oclusais, após o condicionamento ácido, lavagem e secagem da mesma forma descrita anteriormente, foi utilizado o adesivo monocomponente Prime \& Bond 2.1, aplicando-se uma fina camada com pincel do tipo Microbrush, seguido de leve jato de ar, esperando 30 segundos e fotopolimerizando por 10 segundos. Uma segunda camada do adesivo foi sobreposta à primeira, procedendo-se da mesma maneira, conforme as recomendações do fabricante. Foi utilizado porta-matriz TDV com matriz transparente e o apoio obtido através do uso de cunhas de madeira. As cavidades foram restauradas uma a uma, a 
medida que foi sendo concluída a aplicação do adesivo, com dois incrementos de resina composta Solitaire, condensados (Santos et al., 1998; Nash et al., 1998; Resinas, 1998) com condensadores de resina do tipo teflon e fotopolimerizados individualmente por 40 segundos. Os excessos foram eliminados com lâmina de bisturi $\mathrm{n}^{\mathrm{o}} 15$, pontas diamantadas de granulação fina e ultra-fina, lixas abrasivas nas faces proximais e, nas superfícies oclusais, o polimento foi realizado com o sistema de acabamento e polimento Enhance. Após acabamento e polimento, todas as amostras foram imersas em água destilada por 24 horas antes da ciclagem térmica. (Crim \& Garcia-Godoy, 1987; Retief et al., 1989; Cardoso \& Plácido, 1998).

\subsection{Procedimento de ciclagem térmica}

Todos os grupos foram submetidos à ciclagem térmica, realizada em equipamento que consiste de dois reservatórios de água em temperaturas diferentes (frio e quente), regulado por termostato com precisão de $0,1^{\circ}$ C. O aparelho (Fig. 1) apresenta, ainda, um braço móvel no qual acopla-se um recipiente para colocação das amostras e, através de movimentos mecânicos, translada-se de um banho para outro, automaticamente, de acordo com a programação eletrônica, quanto ao tempo de duração em cada banho e o número de ciclos necessários. 
As amostras foram submetidas a 700 ciclos térmicos, com 60 segundos em cada banho, nas temperaturas de $5^{\circ} \mathrm{C}$ a $55^{\circ} \mathrm{C}$, com intervalo transferência de 6 segundos entre os banhos.

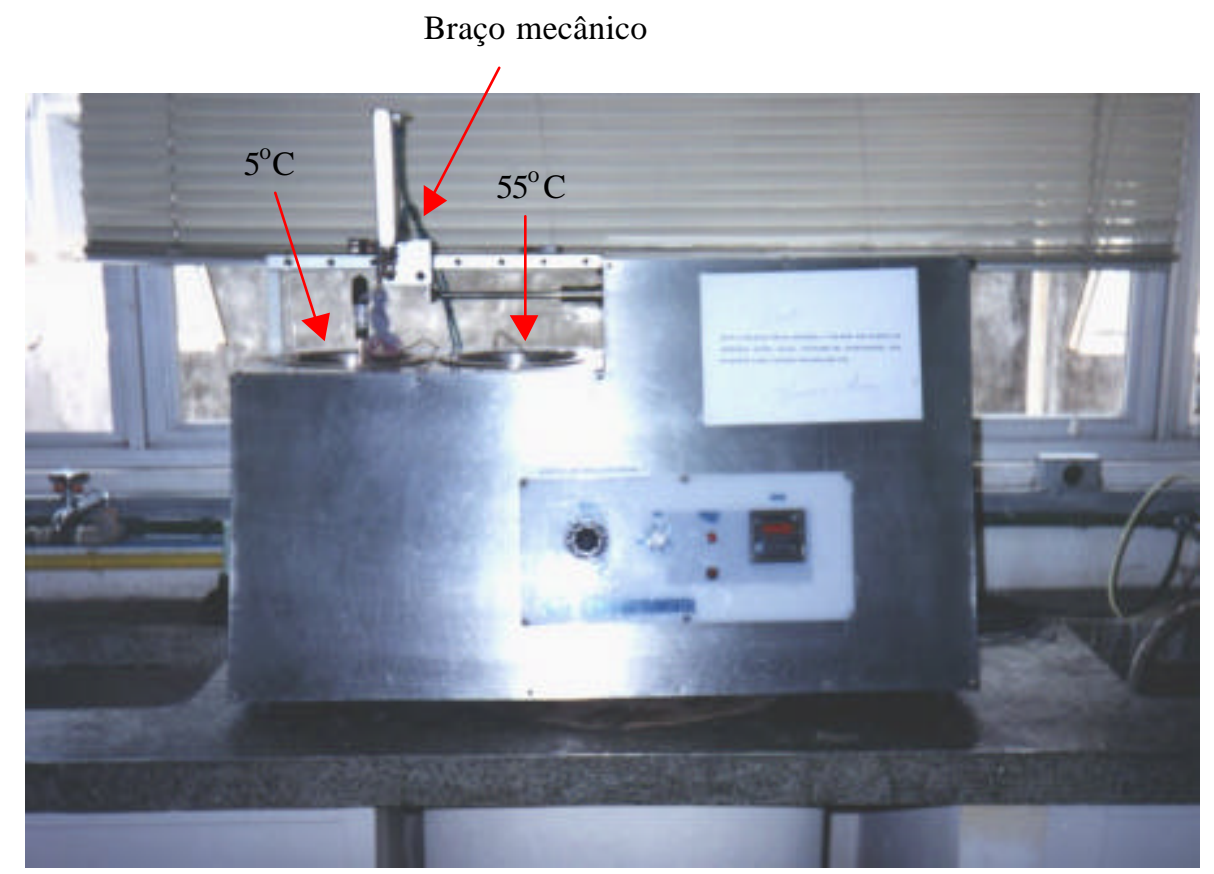

Figura 1 - Máquina de ciclagem térmica, observar as cubas de água a $5^{\circ} \mathrm{C}$ e a $55^{\circ} \mathrm{C}$ e o braço mecânico transportando as amostras. 


\subsection{Procedimento de impermeabilização das amostras}

As raízes remanescentes foram cortadas com disco de carborundum e a base do dente foi recoberta com uma camada de resina acrílica autopolimerizável, do tipo Ortoclas, para se obter melhor vedamento, impedindo a penetração do corante através dessa região. A seguir, foram aplicadas duas camadas de esmalte cosmético, vermelho, pinceladas em toda a superfície do dente, exceto em uma faixa, localizada na face proximal, incluindo toda a restauração e ultrapassando $2 \mathrm{~mm}$ da interface do dente e do material restaurador, para permitir o contato com o corante. O objetivo da utilização do esmalte é impedir a penetração do corante através de qualquer região que não fosse a interface dente/resturação.

\subsection{Procedimento de imersão em solução corante}

Após impermeabilização, as amostras foram imersas em solução de Nitrato de Prata a 50\% (Tay et al., 1995; Camps et al., 1996), pH 6.7 e deixadas no escuro por duas horas. Logo após, foram lavadas em água corrente, por um minuto e 
imersas em água destilada, por mais um minuto, para remover as partículas de prata aderidas à superfície. Em seguida, foram mergulhadas no revelador fotográfico (Kodak), por um período de oito horas, sob luz fluorescente, com finalidade de precipitar as partículas de prata. Findo esse período, os dentes foram lavados com água destilada para remover o revelador e estocados em água destilada até serem cortados para posterior leitura (Wu et al., 1983).

\subsection{Seccionamento das amostras}

As amostras, num total de 24 , foram primeiramente seccionadas no sentido vestíbulo-lingual, com disco de carborundum, resultando em 48 partes. A seguir, foram acomodadas em formas de gelo vazias, com as respectivas marcas, duplicadas em pequenos quadrados de papel sulfite, posicionados lateralmente às restaurações, indicando, com tinta esferográfica, o modo de armazenamento e o adesivo usado. Posteriormente, foi vertida por sobre essas amostras, resina acrílica autopolimerizável (Resigel + Luperox), incluindo-as totalmente, assim como suas respectivas marcações. Após a polimerização da resina, as 48 amostras foram retiradas das formas de gelo, aplainadas em máquina politriz (Fig. 2), que contém um disco de lixa no 120, velocidade variável, programável e constante refrigeração líquida. O objetivo desse procedimento é de facilitar a adaptação na máquina de 
seccionamento LABCUT 1010 - EXTEC (Fig. 3). A seguir, foram posicionadas na máquina de seccionamento e, novamente cortadas, agora no sentido mésio-distal, seccionando o centro da restauração com disco diamantado e refrigerado através de uma mistura de água e óleo mineral, a uma velocidade estável e programada de 250 rpm, obtendo-se 96 espécimes.

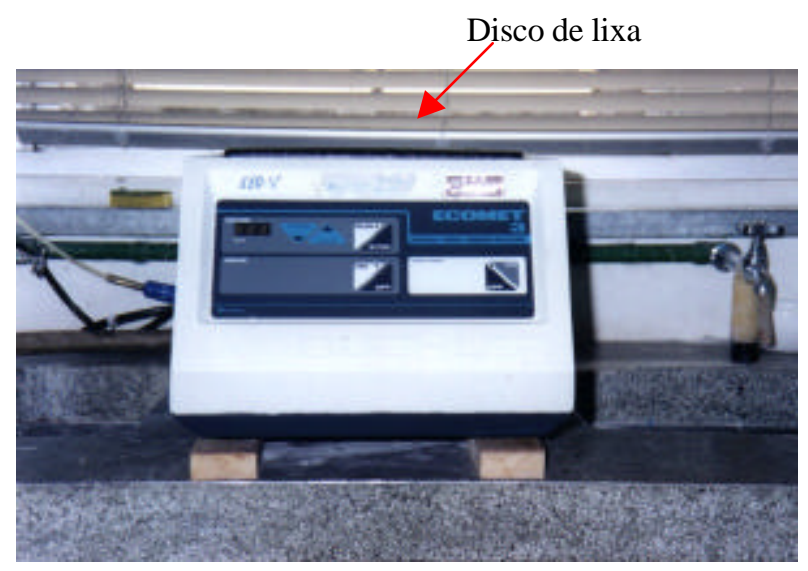

Figura 2 - Máquina politriz utilizada para o aplainamento da resina de inclusão das amostras.

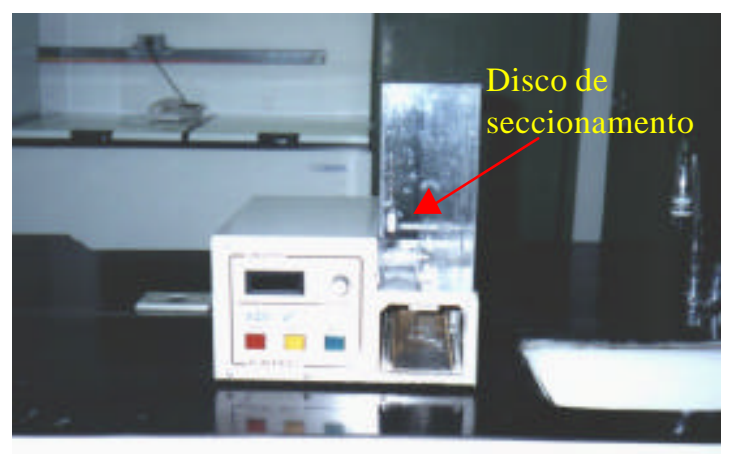

Figura $3-$ Máquina de seccionamento Labcut 1010, utilizada para o seccionamento final das amostras. 


\subsection{Processo de avaliação}

A avaliação da microinfiltração das amostras foi realizada através de um conjunto de equipamentos, composto por scanner e microcomputador com software denominado DIRACON III (Fig. 4), desenvolvidos no LIDO. Os valores da microinfiltração foram mensurados nesse sistema de imagens digitalizadas e as medidas apresentadas em milímetros $(\mathrm{mm})$ de microinfiltação. Foram avaliadas duas posições, a interface dente-restauração da parede axial e, da parede cervical, perfazendo o total de 192 medidas.

Antes do início da leitura, houve calibração das imagens para que todas pudessem ser avaliadas de forma padronizada. A avaliação da microinfiltração foi executada por um avaliador, previamente treinado, não responsável pela execução das amostras e desconhecedor dos grupos a que pertenciam cada amostra. Para avaliar a sensibilidade e possibilidade de reprodução do experimento, $20 \%$ da amostra foi avaliada por um segundo avaliador, também anteriormente treinado. 


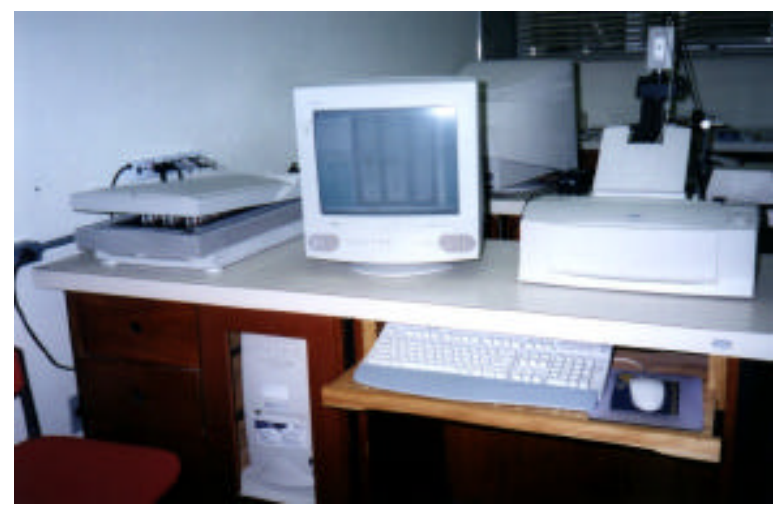

Figura 4 - Micro computador e scanner com software Diracon III, para a medição dos valores de microinfiltração nas amostras. 


\subsection{Análise estatística}

Após tabulação dos dados, os mesmos foram submetidos a Análise de

Variância para avaliar diferenças estatisticamente significantes entre os grupos. 


\section{RESULTADOS}

Os valores de microinfiltração foram obtidos de amostras, devidamente preparadas, como foi descrito anteriormente e podem ser visualizadas nas Figuras 5, 6 e 7.

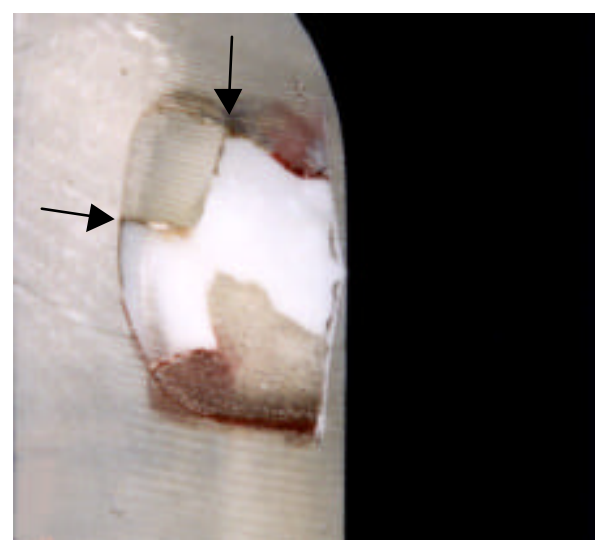

Figura 5 - Amostra incluída na resina, após o corte, demonstrando a penetração do corante nas interfaces das paredes axial e cervical. 


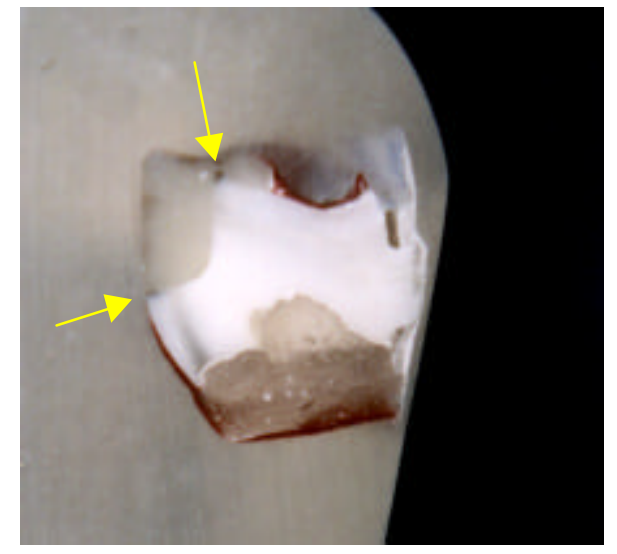

Figura 6 - Amostra incluída na resina, após o corte, demonstrando menor infiltração do corante nas interfaces das paredes axial e cervical

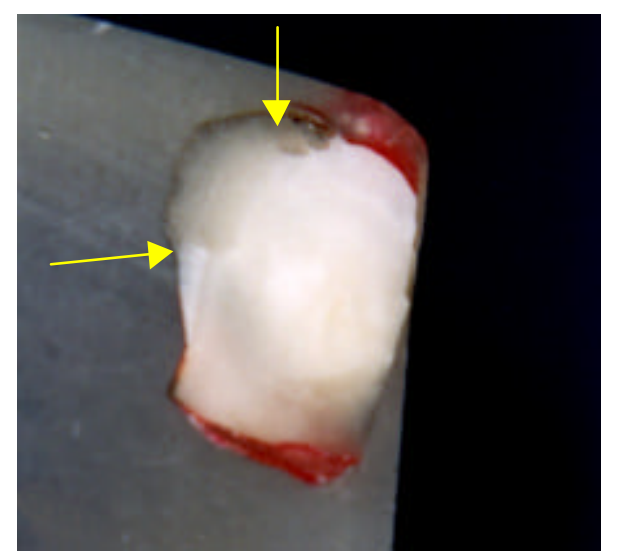

Figura 7 - Amostra incluída na resina, após o corte, demonstrando ausência de infiltração do corante nas interfaces das paredes axial e cervical

Os dados iniciais foram computados com precisão de centésimos de milímetros, através de medições com o software Diracon III, para a avaliação da microinfiltração marginal nas restaurações realizadas com a resina Solitaire. A seguir, foram submetidos a análise de variância, utilizando o recurso split-plot, divididos em dois blocos, o que aumenta a sensibilidade da análise, fornecendo resultados mais acurados, e que se encontram dispostos na Tabela 5.1.

Os valores de microinfiltração correspondentes aos fatores principais armazenamento, material, interface e suas interações se interagem na referida Tabela. Em relação ao modo de armazenamento não houve diferença estatisticamente significante na microinfiltração das amostras, independente do material e da interface 
dente-restauração das paredes axiais e cervicais. Houve, porém, diferenças estatisticamente significantes, com segurança de 99,9\% quando comparadas as medições na interface axial e cervical, demonstrando maior microinfiltração na margem cervical. São também estatisticamente significantes, com segurança de $95 \%$ as interações dos fatores principais armazenamento, material e interface.

TABELA 5.1 - Análise de variância dos valores de microinfiltração correspondentes aos fatores principais armazenamento, adesivo e interface, e suas interações

\begin{tabular}{|c|c|c|c|c|}
\hline Fonte de variação & G.L. & $\begin{array}{l}\text { Soma dos } \\
\text { quadrados }\end{array}$ & $\begin{array}{l}\text { Quadrados } \\
\text { médios }\end{array}$ & $(\mathrm{F})$ \\
\hline Armazenamento (A) & 2 & 0,1830 & 0,0915 & $0,30 \mathrm{~ns}$ \\
\hline Material (M) & 1 & 0,6924 & 0,6924 & $2,28 \mathrm{~ns}$ \\
\hline Interação (A x M) & 2 & 0,3323 & 0,1662 & $0,55 \mathrm{~ns}$ \\
\hline Resíduo I & 90 & 27,3118 & 0,3035 & - \\
\hline Interface (I) & 1 & 2,1611 & 2,1611 & $15,85 * * *$ \\
\hline Interação (I x A) & 2 & 0,4249 & 0,2124 & $1,56 \mathrm{~ns}$ \\
\hline Interação (I x M) & 1 & 0,0142 & 0,0142 & $0,10 \mathrm{~ns}$ \\
\hline Interação (I x A x M) & 2 & 1,1363 & 0,5681 & $4,17 *$ \\
\hline Resíduo II & 90 & 12,2727 & 0,1364 & - \\
\hline Total & 191 & 44,5287 & - & - \\
\hline
\end{tabular}

Na Tabela 5.2 encontram-se as médias em milímetros, correspondentes aos fatores principais armazenamento, material e interface. Embora as médias resultantes do modo de armazenamento não tenham apresentado diferenças estatisticamente significantes, pode-se dizer que as médias numéricas das amostras do grupo Desidratado sugerem microinfiltração ligeiramente maior que as do grupo Hidratado, seguidas dos Congelados (Gráfico 1). Mesmo não apresentando 
diferenças estatisticamente significantes, as médias para os tipos de adesivo mostram diferença numérica sugestiva, comparando-se o Scotchbond Multi-Uso $(0,41 \mathrm{~mm})$ e Prime \& Bond $2.1(0,29 \mathrm{~mm})$ (Gráfico 2), com maior microinfiltração para o primeiro. Houve, porém, diferenças significantes com segurança de 99,9\% para fator Interface, quando comparada as médias das interfaces axial $(0,24 \mathrm{~mm})$ com a cervical (0,46 mm) (Gráfico 3), demonstrando maior infiltração nesta última .

TABELA 5.2 - Médias de microinfiltração em milímetros correspondentes aos fatores principais armazenamento, material e interface

\begin{tabular}{|c|c|c|}
\hline \multicolumn{2}{|c|}{ Armazenamento } & \multirow{2}{*}{ Significância (\%) } \\
\hline Congelado & Hidratado & \\
\hline 0,32 & 0,35 & \multirow{4}{*}{ ns } \\
\hline \multicolumn{2}{|c|}{ Material } & \\
\hline \multicolumn{2}{|c|}{ Scotchbond Multi-Uso } & \\
\hline \multicolumn{2}{|c|}{0,41} & \\
\hline \multicolumn{2}{|c|}{ Interface } & \multirow{3}{*}{0,1} \\
\hline \multicolumn{2}{|c|}{ Axial } & \\
\hline \multicolumn{2}{|c|}{0,24} & \\
\hline
\end{tabular}




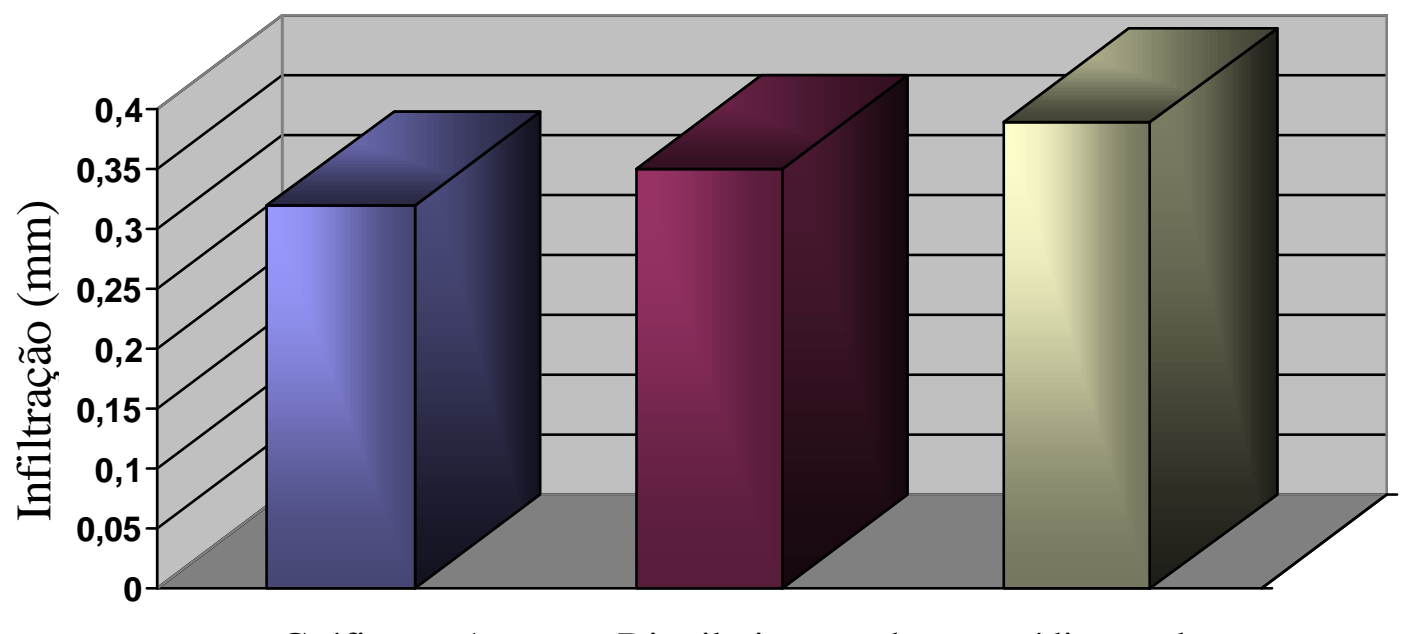

Gráfico 1 - Distribuição das médias de microinfiltração em milímetros, correspondente ao modo de armazenamento.

Legenda

$\square$ Congelado

$\square$ Hidratado

Desidratado

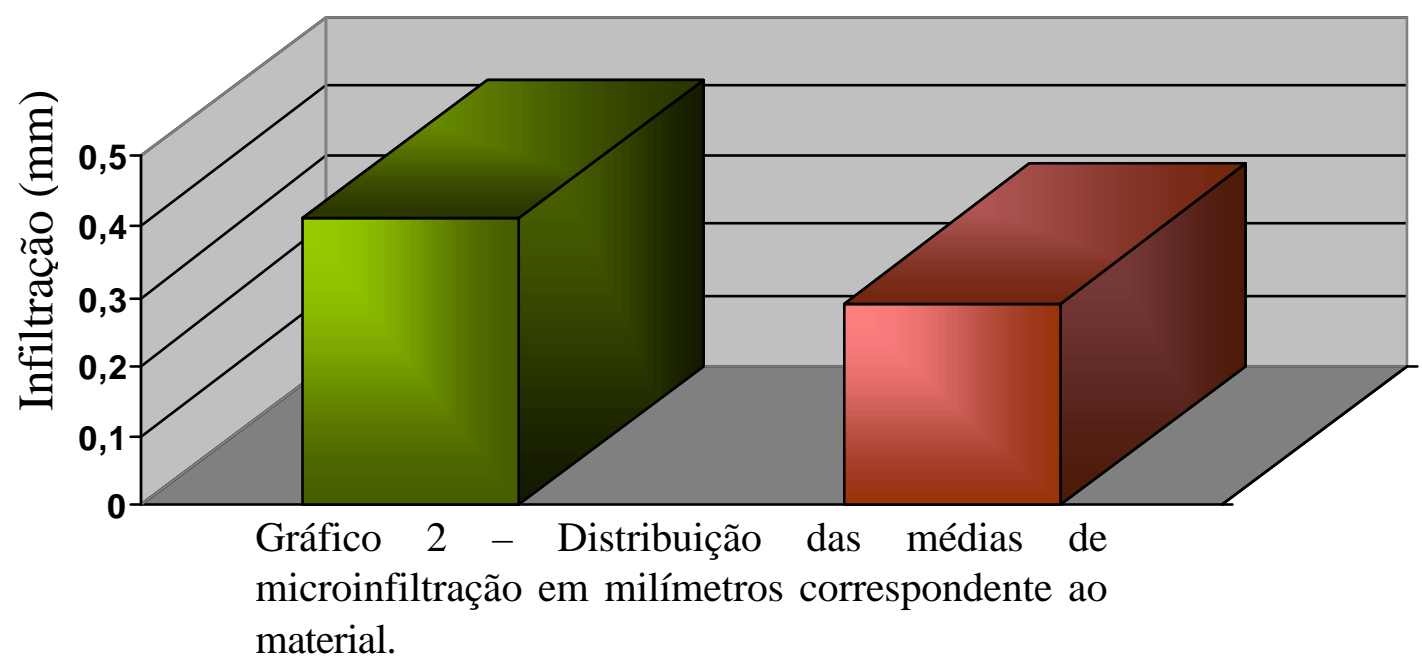

Legenda

$\square$ Scotchbond Multi-Uso

$\square$ Prime \& Bond 2.1 


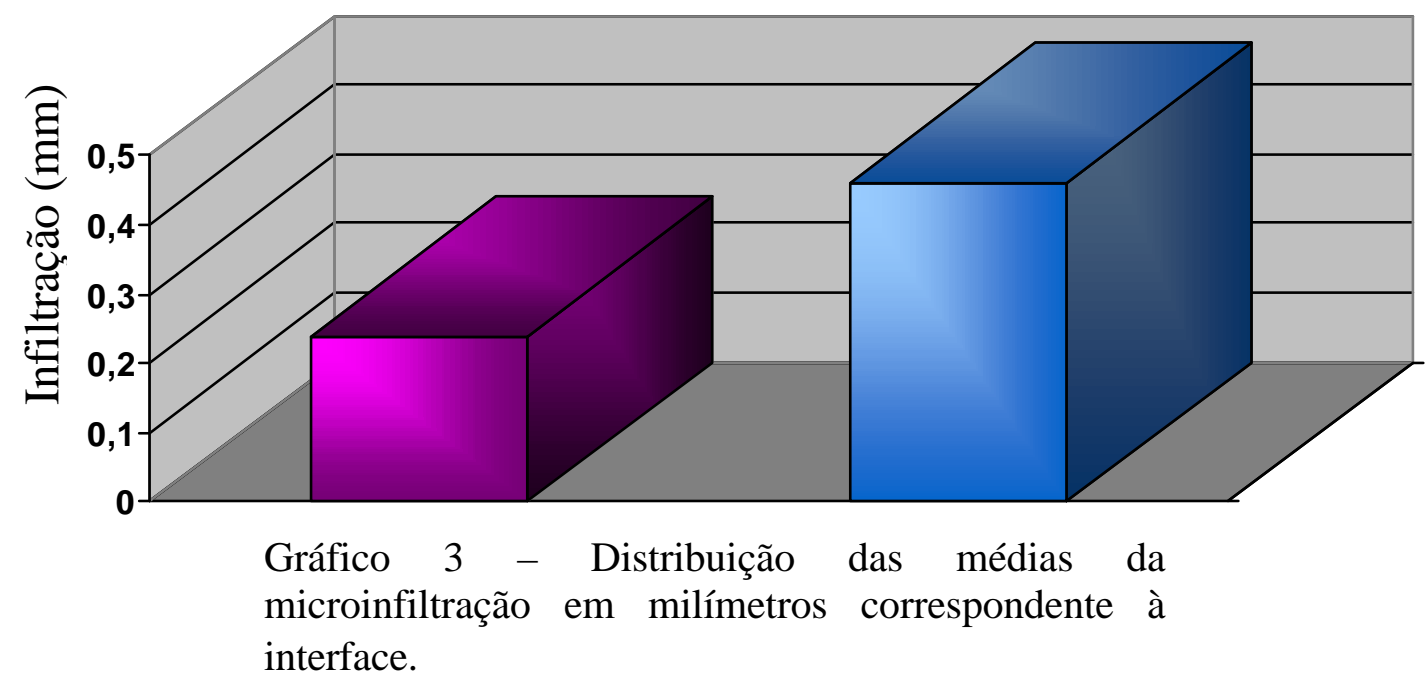

Legenda

Axial

$\square$ Cervical

Os valores das médias de microinfiltração dos fatores principais armazenamento $\mathrm{x}$ material $\mathrm{x}$ interface se interagem na Tabela 5.3 e estão representados pelo Gráfico 4. Demonstram que não houve diferenças estatisticamente significantes, exceto para os valores entre as amostras do grupo Desidratado, quando restauradas com o adesivo Prime \& Bond 2.1, nas interfaces dente-restauração das paredes axiais e cervicais. 
TABELA 5.3 - Médias de microinfiltração em milímetros correspondentes à interação armazenamento $\mathrm{x}$ material $\mathrm{x}$ interface e valor crítico para contraste

\begin{tabular}{c|c|c|c|c|c}
\hline \multirow{2}{*}{ Material } & \multirow{2}{*}{ Interface } & \multicolumn{3}{|c|}{ Armazenamento } & \multirow{2}{*}{ Tuckey (5\%) } \\
\cline { 3 - 5 } & & Congelado & Hidratado & Desidratado & \\
\hline \hline \multirow{2}{*}{$\begin{array}{c}\text { Scotchbond } \\
\text { Multi-Uso }\end{array}$} & Axial & 0,33 & 0,22 & 0,38 & \\
\cline { 2 - 5 } & Cervical & 0,52 & 0,50 & 0,51 & \multirow{2}{*}{0,438} \\
\hline \multirow{2}{*}{$\begin{array}{c}\text { Prime \& } \\
\text { Bond 2.1 }\end{array}$} & Axial & 0,10 & 0,37 & 0,05 & \\
\cline { 2 - 5 } & Cervical & 0,30 & 0,31 & 0,60 & \\
\hline
\end{tabular}

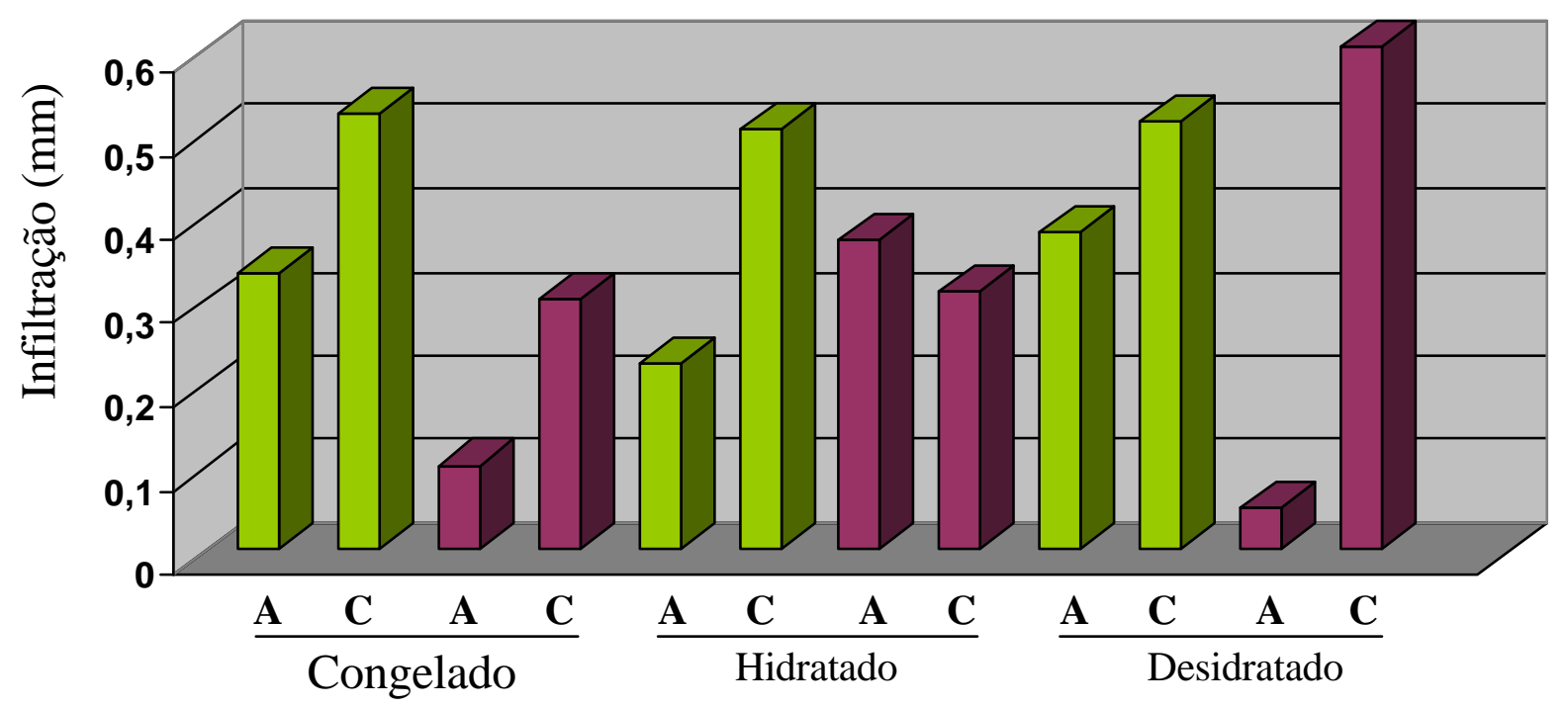

Gráfico 4 - Distribuição das médias de microinfiltração em milímetros correspondentes à interação armazenamento x material $\mathrm{x}$ interface

Legenda

Scotchbond Multi-Uso

Prime \& Bond 2.1 


\section{DISCUSSÃO}

O vedamento hermético da interface dente-restauração tem sido objeto de diversas pesquisas, e seu controle pode ser conseguido através das próprias características estruturais do dente, da destreza profissional e da ausência de contaminação durante o preparo cavitário (Smith, 1978). As pesquisas realizadas para avaliação da microinfiltração in vitro tentam simular as condições in vivo, não havendo todavia metodologia padronizada, totalmente definida, para tais investigações (Wu 1983; Crim \& Garcia-Godoy, 1987; Bränström, 1992; Haller, 1993; Tay, 1995; Camps, 1996; Bussadori, 1997; Araújo, 1998). Além disso, é fundamental o conhecimento das características estruturais da dentina (Watanabe \& Nakabayiashi, 1994) e inúmeros são os métodos desenvolvidos para medir a microinfiltração, entre eles a utilização de corantes, como sais de prata $(\mathrm{Wu}$, et al., 1983; Tay, 1995; Gale \& Darvel, 1997) também utilizados neste estudo.

Para a realização de pesquisas in vitro, é necessário que se faça a coleta e o armazenamento dos dentes, até que se obtenha número suficiente de amostras. Sempre que se trabalha com dentes extraídos, estes devem ser submetidos a métodos 
de desinfecção ou esterilização como autoclave (Pashley et al., 1993; Dewald,1997 e Groth et al., 1998) que, por ser um método seguro, foi utilizado neste trabalho. Já, para o armazenamento, diversas soluções são empregadas, e a mais comumente usada é a solução fisiológica, tanto acrescida de agentes antibacterianos (Causton \& Johnson, 1979; Goodis et al., 1991; Goodis et al.,1993; Camps et al., 1996; Lam May Cheng \& Gulabivala, 1996; Strawn et al., 1996), como na forma pura (Causton \& Johnson,1979; Kimura et al., 1985; Cooley \& Dogde, 1989; Retief, 1989; Hawkins, 1997; Araújo, 1998).

O tempo de armazenamento de dentes extraídos é uma variável considerada importante por muitos autores, e apresentou influência significante nos estudos de Strawan et al. (1996); Beech et al. (1991); Goodis et al. (1991). Não demonstrou, porém, significância na maioria dos trabalhos pesquisados (Outhwaite et al., 1976; Mitchen \& Gronas (1986); Crim \& Garcia Godoy, 1987; Cooley \& Dodge, 1989; Retief et al., 1989), portanto não foi objetivo do nosso estudo avaliar essa variável.

O meio de armazenamento de dentes extraídos, entretanto, pode provocar alterações químicas e óticas na superfície dentinária (Strawn et al., 1996); afetar a resistência adesiva (Causton \& Jonhson, 1979; Kimura, 1985; Retief, 1989; Beech, et al. 1991; Dewald, 1997); influenciar a permeabilidade da dentina (Goodis et al., 1991; Goodis et al., 1993); interferir na remoção de dentina por ação de instrumentos endodônticos padronizados (Lam May Cheng \& Gulabivala, 1996) e influenciar a própria microinfiltração (Bränström, 1992; Haller, 1993; Araújo, 1998). 
Para outros autores, a forma de armazenamento de dentes não afetou a resistência adesiva como nos estudos de Mitchem \& Gronas (1986); Aboush \& Jenkins (1983); Cooley \& Dodge (1989); Burrow et al. (1994); nem a permeabilidade dentinária (Outhwaite et al., 1976; Camps et al., 1994) ou a desmineralização por ácido cítrico (Hawkins et al., 1997).

Neste trabalho foi avaliada a influência do modo de armazenamento e do tipo de adesivo na microinfiltração das paredes axiais e cervicais de dentes decíduos, restaurados com resina composta. Após o processamento das amostras, os dados obtidos foram submetidos à análise de variância para a avaliação da microinfiltração. Para isso, esses dados iniciais foram medidos com precisão de centésimos de milímetros, em equipamentos específicos. Os resultados demonstraram que não houve diferença estatisticamente significante na microinfiltração, em relação ao modo de armazenamento, mesmo quando se variou o tipo de material, como demonstra a Tabela 5.1. Esse fato pode ter ocorrido, provavelmente pela associação de fatores, como a padronização da profundidade do preparo (aproximadamente 2 $\mathrm{mm}$, sendo $1 \mathrm{~mm}$ em esmalte e $1 \mathrm{~mm}$ em dentina), que manteve uma distância relativa da polpa, confirmando o estudo de Mitchem \& Gronas (1986) em que, além de o modo de armazenamento não ter influenciado significantemente os resultados, a maior resistência adesiva foi conseguida à distância de $2 \mathrm{~mm}$ da polpa. Da mesma forma, a pesquisa de Outhwaite et al. (1996) demonstrou que quanto menos se aprofunda na dentina, maior é a permeabilidade dentinária e, consequentemente, melhor a adesão. Outro fator que pode ter contribuído para a uniformidade dos resultados, pode ter sido a imersão simultânea de todas as amostras em água 
destilada por um período 24 horas, após o acabamento e polimento da restauração, o que promove absorção de água pela resina composta, expandindo a restauração e melhorando o selamento marginal. Crim \& Garcia-Godoy (1987) também observaram melhores resultados na microinfiltração com os dentes que permaneceram imersos por 24 horas após o término da restauração, antes de serem submetidos à ciclagem térmica, do que com aqueles que foram levados à ciclagem imediatamente, sem esse tempo prévio de imersão. Além disso, como apenas um tipo de resina composta foi utilizado, toda a alteração dimensional sofrida pelo material foi uniforme e, mesmo os adesivos sendo de marcas comerciais diferentes, as alterações referentes a eles foram mínimas, uma vez que são comprovadamente eficientes, pela maioria das pesquisas. Nos estudos de Cooley \& Dodge (1989), o período e o meio de armazenamento não influenciaram significantemente os resultados quando três sistemas adesivos foram testados. Portanto, para esses autores, parece que o prazo de validade e a estabilidade dos materiais são mais importantes do que o meio ou o período de armazenamento.

Embora as médias de microinfiltração correspondentes ao modo de armazenamento e material não tenham apresentado diferenças significantes (Tabela 5.2 e Gráfico 1), os valores numéricos sugerem que as amostras do grupo Desidratado permitiram maior infiltração que os do grupo Hidratado, e que as amostras do grupo Congelado apresentaram desempenho melhor do que ambos. Resultados semelhantes, também foram obtidos por Araújo et al., 1998, com o maior grau de infiltração para os dentes desidratados e o menor, para os dentes congelados, confirmando os resultados obtidos por Camps et al. (1996) e Bränntrön et al. (1992), 
que também encontraram microinfiltração significantemente menor em dentes congelados. Isso pode ser atribuído ao fato de que os adesivos reagem também com a parte orgânica da dentina, e talvez essa parte orgânica possa ser conservada em melhores condições, através do congelamento. Além disso as amostras do Grupo Hidratado foram armazenada em soro fisiológico, pois apesar de ser essa solução muito utilizada em pesquisas de materiais odontológicos, seu emprego tem sofrido algumas restrições, pela interferência sobre a permeabilidade dentinária (Goodis et al. 1991; Goodis et al. 1993).

A Tabela 5.2 e o Gráfico 2, mostram também que mesmo não apresentando diferença estatisticamente significante, as médias relativas ao material apresentam diferença numérica sugestiva de maior microinfiltração para o Scotchbond Multi-Uso (0,41mm) em comparação ao Prime \& Bond 2.1 (0,29mm). Talvez esse resultado confirme o raciocínio de Burrow et al. (1994), que destacam a importância da qualidade da camada híbrida na resistência adesiva. Aliado a esse fato, o material Prime \& Bond 2.1 pode ter encontrado, de alguma forma, melhores condições de atuação, uma vez que esse sistema monocomponente demonstrou excelentes resultados nos estudos de Finger \& Fritz (1996); Holderegger, et al., (1997); Settembrini, et al., (1997). As médias correspondentes à microinfiltração nas interfaces das paredes axiais e cervicais apresentaram diferenças significantes, com segurança de 99,9\% (Tabela 5.2 e Gráfico 3). Esses resultados foram ratificados por Futatsuki \& Nakata (1994) e Tay et al. (1995), quando demonstraram que a microinfiltração não é uniforme nas margens das restaurações e que a maior 
infiltração ocorre nas margens proximais, provavelmente pela menor espessura do esmalte nessa área da cavidade.

Os valores das médias de microinfiltração da interação dos fatores principais (armazenamento x material x interface), representados na Tabela 5.3 e no Gráfico 4, mostram que não houve diferença estatisticamente significante, exceto para os valores das amostras do grupo Desidratado, com o adesivo Prime \& Bond 2.1, quando se consideram as interfaces das paredes axiais e cervicais. Pode-se observar que houve um comportamento heterogêneo para as médias relativas a esse Grupo, com o mesmo adesivo nas paredes cervicais e axiais. Pois o menor valor numérico para as médias de microinfiltração foi para as amostras do grupo Desidratado, com o adesivo Prime \& Bond 2.1, nas interfaces das paredes axiais das restaurações e o maior valor numérico de microinfiltração foi para as médias das amostras do mesmo grupo, com o mesmo material, porém nas margens cervicais, razão para a diferença ser significante. Na nossa opinião isso pode ter ocorrido por alterações na permeabilidade dentinária, talvez em decorrência do pouco tempo de hidratação das amostras (1 hora), já que nos estudos de Araújo et al. (1998) os dentes foram reidratados por uma semana, associado aos problemas existentes com o esmalte nas margens cervicais (Futatsuki \& Nakata, 1994; Tay et al., 1995; Schuckar \& Geurtsen, 1997; Vianna et al., 1998). Porém, essas observações necessitam de mais estudos para suas confirmações.

A evolução dos sistemas adesivos contribuiu sobremaneira para o controle da microinfiltração (Souza Jr., 1995; Mathias et al., 1997). Isso se deve ao fato de que o processo de adesão dos adesivos modernos não é exclusivamente por 
embricamento mecânico, existindo certa afinidade química entre os seus componentes e os tecidos dentais (Nakabayashi et al., 1982). Mesmo assim, entretanto, não se consegue evitá-la completamente (Perdigão et al., 1996; Gale \& Darvel (1997); Pimenta \& Paiva, 1997; Shuckar \& Geurstsern, 1997; Cardoso \& Plácido, 1998; Alves et al., 1998). Talvez, essa microinfiltração seja conseqüência da sensibilidade da técnica de manipulação (Baratieri, 1998), pois são fundamentais detalhes como a formação da camada híbrida (Ferrari et al., 1997), que muitas vezes só pode ser obtida adequadamente mantendo-se a umidade dentinária (Miranda Jr., 1994; Finger \& Fritz, 1996; Tay et al., 1996). Apesar do rigor das técnicas, algumas modificações podem ser introduzidas para reduzir a microinfiltração (Namem et al., 1996). A associação de adesivos multiuso a diferentes tipos de resina é permitida (Gonçalves et al., 1996), assim como a técnica de inserção da resina e o bisel da parede cervical, que podem não interferir nos resultados de microinfiltração (Vieira, 1991).

Apesar da nova tendência de utilização do condicionamento ácido com soluções de baixas concentrações, ou mesmo sem o condicionamento ácido (Mello et al., 1996), as soluções mais concentradas ainda são bastante usadas, com tempo variando de quinze segundos a um minuto para dentes decíduos (Tostes \& GuedesPinto, 1996-97; Teruya \& Côrrea, 1998). Isso confirma os achados de Ruschel et al., 1996, quando afirmam que as condutas clínicas para dentes decíduos podem ser semelhantes às condutas para permanentes, ou com algumas modificações quando se trabalha com resina composta em dentes decíduos (Vianna et al., 1998). 
A utilização crescente de restaurações de resina composta em molares decíduos (Mathias et al., 1997) estimula o interesse por pesquisas nesse campo. O surgimento das resinas do tipo "condensável” oferece uma nova opção de trabalho que apesar de uma série de vantagens (Resinas, 1998; Santos et al., 1998; Leinfelder et al., 1998), apresentam significante contração de polimerização quando comparadas a um compômero (Vasconcelos \& Matson, 1998). Além disso, apresentam melhor desempenho na microinfiltração quando as restaurações são feitas pela técnica incremental (Poskus et al., 1998), semelhante às técnicas utilizadas para resinas convencionais (Imparato, 1996).

Dessa forma, apesar de muitas pesquisas demonstrarem a influência do meio de armazenamento em seus resultados (Kimura et al., 1985; Retief et al., 1989; Goodis et al., 1991; Bränntröm et al., 1992; Goodis, 1993; Haller et al., 1993; Lam May Cheng \& Gulabivala, 1996; Strawn et al., 1996; Dewald,1997; Araújo et al., 1998), neste estudo, tal influência não foi significante, corroborando com os resultados de outros autores (Outhwaite et al., 1976; Mitchen \& Gronas, 1986; Crim \& Garcia Godoy, 1987; Cooley \& Dodge, 1989; Camps, 1994; Burrow, 1994). Acreditamos que os fatores inerentes aos materiais utilizados e a tentativa de padronização na metodologia do experimento, possam ter sido mais relevantes do que a forma em que os dentes foram conservados. Mais estudos, porém, são necessários para a confirmação real de tais resultados. 


\section{CONCLUSÕES}

Diante dos resultados obtidos, é possível afirmar que:

- A microinfiltração na parede cervical foi estatisticamente significante maior que na parede axial;

- Os modos armazenamento Congelado, Hidratado e Desidratado não apresentaram diferenças estatisticamente significantes entre si.

- Os tipos de adesivos não mostraram diferenças estatisticamente significantes nos três modos de armazenamento, havendo porém diferenças estatisticamente significante nas amostras do grupo Desidratado, com o adesivo Prime \& Bond 2.1, quando consideradas as margens, com maior infiltração na cervical. 


\section{REFERÊNCIAS BIBLIOGRÁFICAS}

1. ABOUSH, Y.E.Y.; JENKINS, C.B.G. The effect of post-extraction storage on the adhesion of glass ionomers to dentin. J Dent Res, v.62, n.4, p.441, 1983. [Resumo n. 273].

2. ALANI, A.H.; TOH, C.G. Detection of microleakage around dental restorations: a review. Oper Dent, v.22, n.4, p.173-185, July 1997.

3. ALVES, A.; MYAKI, S.I.; RODRIGUES, C.R.M.D.; RODRIGUES FILHO, L.E.; ANDO,T. Infiltração marginal em restaurações Classe II de molares decíduos utilizando-se uma resina composta de baixa viscosidade como base. J Bras Pediatr, v.1, n.3, p.35-40, 1998.

4. ARAÚJO, R.M.; ARAÚJO, M.A.M.; SILVA, R.C.S.P.; GONÇALVES, S.E.P.; HUHTALA, M.F.R.L.; RODRIGUES, J.R. Influência de diferentes meios de armazenamento de dentes extraídos na infiltração marginal. In:

\footnotetext{
* De acordo com NBR - 6023 da Associação Brasileira de Normas Técnicas, 1989, abreviatura de
} periódicos segundo "Index to Dental Literature". 
5. REUNIÃO ANUAL DA SOCIEDADE BRASILEIRA DE PESQUISA ODONTOLÓGICA, 1998, Águas de São Pedro. Anais... Águas de São Pedro: SBPqO,1998. p.14. [Resumo n. A025]

6. BARATIERI, L.N.; MONTEIRO Jr., S.; RITTER, A.V.; FELIPPE, L.A. Materiais de forramento: usar ou não usar? Quais? In: GONÇALVES, E.A.N.; FELLER, C. Atualização na clínica odontológica. São Paulo: Artes Médicas, 1998. Cap.2. p.31-59.

7. BEECH, D.R.; TYAS, M.J.; SOLOMON, A. Bond strength of restorative materials to human dentin: influence of post-extraction time. Dent Mater, v.7, n.1, p.15-17, Jan. 1991.

8. BRÄNNSTRÖM, M.; COLI, P.; BLIXT, M. Effect of tooth storage and cavity cleansing on cervical gap formation in Class II glass-ionomer/composite restorations. Dent Mater, v.8, n.5, p.327-331, Sept. 1992.

9. BURROW, M.F.; TAKAKURA, H.; NAKAJIMA, M.; INAI, N.; TAGAMI, J.; TAKATSU, T. The influence of age and depth of dentin on bonding. Dent Mater, v.10, n.4, p.241-246, July 1994.

10. BUSSADORI, S.K. Microinfiltração em dentes decíduos em função de materiais e condicionamento ácido. São Paulo, 1997. 73p. Tese (Mestrado em Materiais Dentários) - Faculdade de Odontologia da Universidade de São Paulo. 
11. CAMPS, J.; BAUNDRY, X.; BORDES, V.; DEJOU, J.; PIGNOLY, C.; LADEQUE, P. Influence of tooth cryopreservation and storage time on microleakage. Dent Mater, v.12, n.2, p.121-126, Mar. 1996.

12. CAMPS, J.; MARTIN, P.; LADEQUE, P.; RIEU, R.; FUSERI, J. Influence of tooth cryopreservation on human dentin permeability, in vitro. Dent Mater, v.10, n.3, p.210-214, May 1994.

13. CARDOSO, P.E.C.; PLÁCIDO, E. Microinfiltração de restaurações de Cl. V em resina composta usando oito novos adesivos hidrofílicos. In: REUNIÃO ANUAL DA SOCIEDADE BRASILEIRA DE PESQUISA ODONTOLÓGICA, 1998, Águas de São Pedro. Anais... Águas de São Pedro: SBPqO,1998. p.18. [Resumo n. A037].

14. CAUSTON, B.E.; JOHNSON, N.W. Changes in the dentine of human teeth following extraction and their implication for in vitro studies of adhesion to tooth substance. Arch Oral Biol, v. 24, n. 3, p.229-232, 1979.

15. COOLEY, R.L., DODGE, W.W. Bond strenght of three dentinal adhesives on recently extracted versus aged teeth. Quintecensse Int, v.20, n.7, p.513$516,1989$.

16. CRIM, G.A.; GARCIA-GODOY, F. Microleakage: the effect of storage and cycling duration. J Prosthet Dent, v.57, n.5, p.574-576, May 1987.

17. DEWALD, J.P. The use of extracted teeth for in vitro bonding studies: a review of infection control considerations. Dent Mater, v.13, n.2, p.74-81, Mar. 1997. 
18. FERRARI, M.; GORACCI, G.; GARCÍA-GODOY, F. Bonding mechanism of three "one-bottle" systems to conditioned and unconditioned enamel and dentin. Am J Dent, v.10, n.5, p.224-230, Oct. 1997.

19. FINGER, W.J.; FRITZ, U. Laboratory evaluation of one-component enamel/dentin bonding agents. Am J Dent, v.9, n.5, p.206-10, Oct. 1996.

20. FUTATSUKI, M.; NAKATA, M. In vitro marginal leakage of class II composite resin restorations by thermal cicling. J Clin Pediatr Dent, v.18, n.3, p.191-196, 1994.

21. GALE, M.S.; DARVEL, B.W. Controlling dentina penetration in computer microleakage tracer mapping. J Dent, v.25, n.2, p.129-136, Mar. 1997.

22. GONÇALVES, S.E.P.; ARAÚJO, M.A.M.; PADILHA, R.Q. Adesivos multiuso: avaliação da resistência adesiva à dentina ante o teste de cisalhamento. Rev Odontol UNESP, v.25, p.113-121, 1996. Número especial.

23. GOODIS, H.E.; MARSHALL Jr., G.W.; WHITE, J.M. The effects of storage after extraction of the teeth on human dentine permeability in vitro. Arch Oral Biol, v.36, n.8, p.561-566, 1991.

24. GOODIS, H.E.; MARSHALL Jr., G.W.; WHITE, J.M.; GEE, L.; HORNBERGER, B.; MARSHALL, S.J. Storage effects on dentin permeability and shear bond strengths. Dent Mater, v.9, n.2, p.79-84, Mar. 1993. 
25. GROTH, E.D.B.; SANTOS, F.A.M.; KURAMOTO Jr., M.; MATSON, E. Avaliação dos efeitos da esterilização nas propriedades adesivas da dentina. In: REUNIÃO ANUAL DA SOCIEDADE BRASILEIRA DE PESQUISA ODONTOLÓGICA, 1998, Águas de São Pedro.. Anais... Águas de São Pedro: SBPqO, 1998. p. 18. [Resumo n. A039].

26. HALlER, B.; HOFMANN, N.; KLAIBER. B.; BLOCHING, U. Effect of storage media on microleakage of five dentin bonding agents. Dent Mater, v.9, n.3, p.191-197, May 1993.

27. HAWKINS, C.; STERRET, J.D.; RUSSEL, C. Citric acid demineralization of cementum and dentin: the effect of the storage medium. $\mathbf{J}$ Clin Periodontol, v.24, n.4, p.267-271, Apr. 1997.

28. HOLDEREGGER, C.; PAUL, S.J.; LÜTHY, H.; SCHÄRER, P. Bond strength of one-bottle dentin bonding agente on human dentin. Am J Dent, v.10, n.2, p.71-76, Apr. 1997.

29. IMPARATO, J.C.P. Avaliação da microinfiltração de quatro técnicas restauradoras com resina composta nas caixas proximais em cavidades de Classe II de molares decíduos. São Paulo, 1996. 93p. Dissertação (Mestrado em Odontopediatria) - Faculdade de Odontologia da Universidade de São Paulo.

30. KIMURA, S.; SHIMIZU, T.; FUJII, B. Influence of dentin on bonding of composite resin - Part 1 - Effect of fresh dentin and storing conditions. Dent Mater J, v.4, n.1, p.68-80, 1985. 
31. LAM MAY CHENG, J.A.; GULABIVALA, K. Influence of storage conditions of extrected teeth on dentine removal by a standardised method of filling. Endod Dent Traumatol, v.12, n.1, p.25-32, Feb. 1996.

32. LEINFELDER, K.F.; NASH, R.W.; RADZ, G.M. A report on a new condensable composite resin. Compend Contin Educ Dent, v.19, n.3, p.230-237, Mar. 1998.

33. MATHIAS, R. S.; KRAMER, P.F.; IMPARATO, J.C.P.; GUEDES-PINTO, A.C. Dentística operatória e restauradora. In: GUEDES-PINTO, A.C. Odontopediatria. 6. ed. São Paulo: Santos, 1997. Cap.33, p.569-607.

34. MELLO, J.B.; AMENDOLA, A.B.; MENDES, A.J.D.; HUHTALA, M.F.R.L. A influência do condicionamento ácido da dentina no selamento marginal de um adesivo. Rev Odontol UNESP v.25, n.1, p.69-77, 1996.

35. MIRANDA Jr., W.G. Avaliação da infiltração “in vitro” em caixas proximais restauradas com resinas compostas e cimento de ionômero de vidro. São Paulo, 1992. 82p. Tese (Mestrado em Dentística Restauradora) - Faculdade de Odontologia da Universidade de São Paulo.

36. MITCHEM, J.C.; GRONAS, D.G. Effects of time after extraction and depht of dentin on resin dentin adhesives. J Am Dent Assoc, v.113, p.285-287, 1986.

37. NAKABAYASHI, N; KOGIMA, K; MASUHARA, E. The promotion of adhesion by the infiltration of monomers into tooth substrates. J Biomed Mater Res, v.16, n.3, p.265-273, May 1982. 
38. NAMEN, F.M.; SÉRGIO, P.P.; SALGADO, L.P.; SAMPAIO, H.; GALAN Jr., J. Adesivos dentinários. Efeito da contração de polimerização. Rev Bras Odontol, v. 53, n.6, p. 10-13, nov./dez. 1996.

39. OUTHWAITE, W.C.; LIVINGSTON, M.J.; PASHLEY, D.H. Effects of changes in surface area, thickness, temperature and post-extraction time on human dentine permeability. Arch Oral Biol, v.21, n.10, p.599-603, 1976.

40. PASHLEY, E.L.; LIWEN, T.; PASHLEY, D.H. Sterilization of human teeth: Its effect on permeability and bond strength. Am J Dent, v.6, n.4, p.189191, Aug. 1993.

41. PERdigÃO, J.; LAMBRECHTS, P.; MEERBEEK, B.V.; BRAEM, M.; YILDIZ, E.; YÜCEL, T.; VANHERLE, G. The interaction of adhesive systems with human dentin. Am J Dent, v.9, n.4, p.167-173, Aug. 1996.

42. PIMENTA, L.A.F.; PAIVA, O.C. Efetividade de adesivos dentinários hidrofílicos no controle da microinfiltração marginal. Rev Assoc Paul Cir Dent v.51, n.2, p.183-187, mar./abr. 1997.

43. POSKUS, L.T.; MEIRA, J.B.C., CARDOSO, P.E.C. Avaliação da microinfiltração e dureza superficial de uma nova resina composta condensável. In: REUNIÃO ANUAL DA SOCIEDADE BRASILEIRA DE PESQUISA ODONTOLÓGICA, 1998,. Águas de São Pedro. Anais... Águas de São Pedro: SBPqO, 1998. p.104. [Resumo n. B028]

44. RESINAS compostas condensáveis. Dent Advisor,. v.5, n.8, p.1-4, set. 1998. 
45. RETIEF, D.H.; WENDT, S.L.; BRADLEY, E.L.; DENYS, F.R. The effect of storage media and duration of storage of extracted teeth on shear bond strength of Scotchbond 2/Silux to dentin. Am J Dent, v.2, n.5, p.269-273, 1989.

46. RUSCHEL, H.C.; SOUZA, M.A.L.; FOSSATI, A.C.M.; CHEVITARESE; SOUZA, P.R. Estrutura dentinária decídua e permanente: princípios para uma conduta clínica racional. Rev ABO Nac v.4, n.3, p.161-165, jun./jul. 1996.

47. SANTOS, J.F.; CARDOSO, P.E.C.; MIRANDA Jr, W.G. Seleção do Material Restaurador. In: GONÇALVES, E.A.N.; FELLER, C. Atualização na clínica odontológica. São Paulo: Artes Médicas, 1998. Cap.6. p.127155 ,

48. SCHUCKAR, M.; GEURTSEN, W. Proximo-cervical adaptation of class IIcomposite restorations after thermocycling: a quantitative and qualitative study. J Oral Rehabil, v.24, n.10, p.766-775, Oct. 1997.

49. SETTEMBRINI, L.; GULTZ, J.P.; SCHERER, W.; KAIM, J. A single component bonding system microleakage study. Gen Dent, v.45, n.4, p.341-343, July 1997.

50. SMITH, G.A., WILSON, N.H.F.; COMB, E.C. Microleakge on conventional and ternary amalgam restorations in vitro. Br Dent J, v.144, p.69-73, 1978. 
51. SOUZA Jr., M.H.S. Adesivos dentinários: evolução, estágio atual e considerações clínicas para sua utilização. Maxi-Odonto Dentística, v.1, n.1, p.1-18, 1995.

52. STRAWN, S.E.; WHITE, J.M.; MARSHALL Jr., G.W.; GEE, L.; GOODIS, H.E.; MARSHALL, S.J. Spectroscopic changes in human dentine exposed to various storage solutions - short term. J Dent, v.24, n.6, p.417-423, Nov. 1996.

53. TAY, F.R., GWINNETT, J.A., WEI, S.H.Y. Micromorphological spectrum from overdrying to overwetting -acid conditioned dentin in water-free acetone-based, single-bottle primer/adhesives. Dent Mater, v.12, n.4, p.236-244, July 1996.

54. TAY, F.R.; PANG, K.M.; GWINNETT, A.J.; WEI, S.H.Y. A method for microleakage evaluation along the dentin/restorative interface. Am J Dent, v.8, n.2, p.105-108, Apr. 1995.

55. TEN CATE, A.R. Histologia bucal: desenvolvimento, estrutura e função. 2 ed. Rio de Janeiro: Guanabara Koogan, 1988. 395p.

56. TERUYA, J.I.; CORRÊA, M.S.N.P. Adesão à estrutura dental-Adesivos dentinários. In: CORRÊA, M.S.N.P. Odontopediatria na Primeira Infância. São Paulo: Santos, 1998. Cap. 679p.

57. TOSTES, M.; GUEDES-PINTO A.C. Efeito do tempo de condicionamento ácido sobre a infiltração marginal de restaurações de resina compósita em 
dentes decíduos. Rev Odontopediatr, v.5, n.2, p.69-74, abr./jun. 19961997.

58. VASCONCELOS, A.B.; MATSON, E. Método mensurador da contração de polimerização linear em materiais foto ativados. In: REUNIÃO ANUAL DA SOCIEDADE BRASILEIRA DE PESQUISA ODONTOLÓGICA, 1998, Águas de São Pedro. Anais... Águas de São Pedro: SBPqO, 1998. p.6. [Resumo n. A003]

59. VIANNA, R.; BASTOS, E.; PRIMO, L. Restaurações proximais em molares decíduos: qual o melhor material? In: GONÇALVES, E.A.N.; FELLER, C. Atualização na Clínica Odontológica. São Paulo: Artes Médicas, 1998. Cap. 18. p.443-464.

60. VIEIRA, R.S. Avaliação in vitro da infiltração marginal de restaurações de Classe II, com resina composta fotoativada, em molares decíduos. São Paulo, 1991. 174p. Tese (Doutorado em Odontopediatria) - Faculdade de Odontologia da Universidade de São Paulo.

61. WATANABE, I.; NAKABAYASHI, N. Measuremente methods for adhesion to dentine: the current status in Japan. J Dent, v.22, p.67-72, 1994.

62. WU, W.; COBB, E.; DERMANN, K.; RUPP, N.W. Detecting margin leakage of dental composite restorations. J Biomed Mater Res, v.17, n.1, p.3743, Jan. 1983. 


\section{SUMMARY}

\section{Influence of the manner of storage and kind of adhesive on the microleakage in primary teeth restorated with composite}

This study evaluated the in vitro influence of the storage manner and two kinds of dentinal adhesive on the microleakage, in axial and cervical walls of composite restorations, in primary second molars. The samples were divided in three groups, according to the storage manner, and named: Desidratado, Hidratado and Congelado. The samples of the Desidratado group were kept dry, the ones of the Hidratado group were stored into phisiological saline solution under refrigeration, and the ones of the Congelado group were kept into the freezer, also immersed into the phisiological solution. Then, the samples received two vertical slot preparations, one mesio-occlusal and the other disto-occlusal. On the mesio-occlusal cavities, the adhesive system Scotchbond Multi-Uso was used, whereas on the disto-occlusal the monocomponent adhesive Prime \& Bond 2.1 were chosen, and all of them were filled with the Solitaire composite. The groups were then thermocicled, before immersion in silver stain solution. In order to evaluate the infiltration of the stain in 
the tooth-restoration interface, the samples were sectioned, first in the vestibulolingual direction, and then included into auto-cure resin to the addaptation onto the secctining machine and receive a second cut in the mesio-distal direction, on the center of the restoration. The microleakage values of the axial and cervical walls were measured by a digitalized image system, presented in milimeters, and submitted to statistical analysis. The obtained results showed that the storage manner has no statistically significant influence on the marginal microleakage of the restorations, however, the microleakage of the cervical wall was significantly greater than of the axial wall, with 99,9\% certainty. The used adhesive systems have not shown significant influence on the microleakage, in the studied storage manners. However, there was a statistically difference in the Desidratado group samples, with the Prime \& Bond 2.1 adhesive, taking in count the margins of the restoration (axial and cervical). 


\section{APÊNDICE}

Dados, em milímetros, obtidos das réplicas.

\begin{tabular}{|c|c|c|c|c|c|c|c|c|c|c|c|}
\hline \multicolumn{4}{|c|}{ CONGELADO } & \multicolumn{4}{c|}{ HIDRATADO } & \multicolumn{3}{c|}{ DESIDRATADO } \\
\hline \multicolumn{2}{|c|}{ Scotchbond } & Prime \& Bond & \multicolumn{2}{|c|}{ Scotchbond } & \multicolumn{2}{c|}{ Prime \& Bond } & \multicolumn{2}{|c|}{ Scotchbond } & \multicolumn{2}{c|}{ Prime \& Bond } \\
\hline Axial & Cerv. & Axial & Cerv. & Axial & Cerv. & Axial & Cerv. & Axial & Cerv. & Axial & Cerv. \\
\hline 0 & 0 & 0 & 0 & 0,91 & 0,34 & 0 & 0 & 1,61 & 0,85 & 0,27 & 1,02 \\
\hline 0 & 0 & 0 & 0 & 0 & 0 & 0,91 & 0,70 & 1,33 & 1,15 & 0 & 0,50 \\
\hline 0 & 0,84 & 0 & 0 & 0 & 1,06 & 1,81 & 1,44 & 0 & 0 & 0 & 0,85 \\
\hline 0 & 1,54 & 0 & 0,34 & 0,17 & 1,10 & 0,61 & 0 & 0 & 0 & 0 & 0 \\
\hline 1,49 & 1,24 & 0 & 0 & 0 & 0,40 & 0 & 0 & 0,88 & 0,90 & 0 & 0,83 \\
\hline 0 & 0 & 0 & 0 & 0,32 & 1,23 & 0,34 & 0,21 & 0,93 & 0,80 & 0 & 0,87 \\
\hline 0 & 0 & 0 & 0,09 & 0,94 & 0,52 & 0,50 & 0,47 & 0,18 & 0 & 0 & 1,22 \\
\hline 0 & 0 & 0 & 0 & 0 & 0,40 & 0,59 & 0,38 & 0 & 0 & 0 & 0 \\
\hline 0,19 & 0,10 & 0 & 0,51 & 0 & 0,77 & 0 & 0 & 0 & 0 & 0 & 0,90 \\
\hline 1,61 & 1,47 & 0,51 & 1,33 & 0,72 & 0 & 0,42 & 0,80 & 0,43 & 0,43 & 0 & 1,00 \\
\hline 1,23 & 0 & 1,12 & 0,64 & 0 & 1,36 & 0 & 0 & 0 & 1,18 & 0,20 & 0 \\
\hline 0,76 & 0,51 & 0 & 0 & 0 & 0 & 0 & 0 & 0 & 0 & 0,40 & 0 \\
\hline 0 & 0,42 & 0 & 0,42 & 0,27 & 0 & 0,68 & 0,08 & 0 & 1,15 & 0 & 0 \\
\hline 0 & 0,80 & 0 & 0 & 0 & 0 & 0 & 0,89 & 0,77 & 1,48 & 0 & 0 \\
\hline 0 & 0,21 & 0 & 0 & 0 & 0,47 & 0 & 0 & 0 & 0 & 0 & 1,10 \\
\hline 0 & 0,13 & 0 & 1,23 & 0,21 & 0,27 & 0 & 0 & 0 & 0,19 & 0 & 1,35 \\
\hline
\end{tabular}

